Revista de Derecho Político, núm. 27-28, 1988, pp. 317-352

\title{
ELECCIONES AL PARLAMENTO EUROPEO
}

POR

ENRIQUE ARNALDO ALCUBILLA

Letrado de las Cortes Generales

\section{INTRODUCCION}

\section{A. El procedimiento electoral uniforme: una todavía lejana utopia}

En virtud del artículo 28.1 del Tratado de Adhesión de España y Portugal a las Comunidades Europeas, hecho en Lisboa y Madrid el 17 de junio de 1985, en el transcurso de los dos primeros años siguientes a la adhesión -es decir, antes del 31 de diciembre de 1987- cada uno de los nuevos Estados miembros procederá a la elección por sufragio universal directo, de los 60 representantes del pueblo español en la Asamblea y de los 24 representantes del pueblo portugués en la Asamblea, respectivamente, de conformidad con las disposiciones del Acta de 20 de septiembre de 1976, relativa a la elección de los representantes en la Asamblea por sufragio universal directo. Estas elecciones tuvieron lugar en nuestro país el 10 de junio de 1987, y en Portugal el 19 de julio de 1987; el mandato de los "eurorepresentantes" expirará al mismo tiempo que el de los representantes elegidos en los Estados miembros actuales para el periodo quinquenal en curso, es decir, en 1989. Para ese momento el principal reto político del Parlamento Europeo, que ya ha alcanzado mayores competencias decisorias respecto del Consejo y la Comisión gracias al Acta Unica Europea, es sin duda lograr la aprobación de un procedimiento electoral común que rija las elecciones directas -las terceras-en 1989.

A pesar de los reiterados fracasos de los proyectos de articulación de un procedimiento electoral uniforme, que han encontrado en el Consejo de Ministros - temeroso de su privilegiada posición institucional en el seno 
de la Comunidad Europea- un valladar inexpugnable, el Parlamento Europeo no se ha dejado en ningún momento arrastrar por el desaliento, pues entiende que aquél constituye un paso adelante imprescindible en el largo camino hacia la consecución de la unidad politica europea y un instrumento necesario para reforzar la legitimidad democrática de una institución que, como afirma LAVILLA RUBIRA, a diferencia de los Parlamentos nacionales, no representa al pueblo soberano y no ocupa, en consecuencia, el status institucional que debería ostentar tal representación ${ }^{1}$.

La importancia y urgencia de la unificación de las normas reguladoras de las elecciones al Parlamento Europeo - que hasta el momento no han sido verdaderas elecciones europeas, sino una simple suma de elecciones nacionales ${ }^{2}$ - reside, entre otras razones, en la necesidad de potenciar la creación de un sistema de partidos europeos y la de evitar los problemas de representatividad que hoy se producen con la diversidad de normativas electorales ${ }^{3}$, diversidad que se traduce - como no puede ser de otra forma- en discrepancias importantes en cuestiones básicas, como el desarrollo del sufragio activo o pasivo, el modo de escrutinio, el tamaño de las circunscripciones, la barrera minima legal para obtener escaño, o la fórmula de expresión del voto, entre otras muchas ${ }^{4}$.

Los distintos proyectos de establecimiento de un sistema electoral uniforme para todos los Estados miembros — cuyas dos últimas expresiones son el proyecto Seitlinger (1982), que tras la aprobación por el Pleno del Parlamento Europeo fue rechazado por el Consejo de Ministros, y el proyecto Bocklet (1985) pendiente aún de aprobación por el Pleno de la Asamblea - mantienen una no censurable prudencia y proponen -lejos de cualquier maximalismo - una uniformidad sólo relativa del sistema electoral en las materias en las que es posible alcanzar el necesario consenso

1 J.J. LaviLla Rubira. La posición institucional del Parlamento Europeo. Revista de las Cortes Generales. núm. 9 (1986) pág. 16. Añade: “Y el Parlamento Europeo no representa al pueblo soberano porque tal pueblo no existe. Si representar significa hacer presente y operante algo que no está realmente presente ni es, por consiguiente, actuante... su presupuesto indispensable es que exista esa unidad que va a ser representada, y el pueblo europeo no existe. El Parlamento Europeo no es un organo representativo y por eso no puede ser considerado un verdadero Parlamenton.

2 J.L. Burban y P. Ginestet. Le Parlement Européen. Qué sais je?, Presses Universitaires de France. Paris. 1981. pág. 18.

3 F. Aldecoa luzarraga y A. Muñoz Alvarez. Hacia una ley electoral uniforme para las elecciones al Parlamento Europeo: problemas que suscita. Revista de Instituciones Europeas. vol. 13. núm. 3. págs. $631-632$.

4 Un análisis de los sistemas electorales del Parlamento Europeo en: F. SANTAOLALLA LOPEz. Sistema electoral del Parlamento Europeo y su repercusión posible en el Derecho Español. Fundación Juan March. Serie Universitaria, núm. 234, Madrid 1986; y J.L. Rulz NAVARRo PInAR. El Parlamento Europeo: sistemas electorales de los diez y alternativas de la futura ley electoral española. Revista de las Cortes Generales núm. 6 (1985). 
entre los países comunitarios, dejando así un amplio margen a la normativa de desarrollo de éstos ${ }^{5}$.

Los mayores problemas se plantean en torno al carácter de las circunscripciones (nacional o múltiple), el sistema de escrutinio (mayoritario o proporcional, con sus distintas variantes), la derogación del principio de nacionalidad como requisito indispensable para el ejercicio de los derechos de sufragio activo y pasivo, y la debatida cuestión del doble mandato.

El debate, sobre esta cuestión permanece, por tanto, abierto y no existen sintomas suficientes que permitan augurar en un futuro próximo una solución satisfactoria, por lo que, y nos gustaría equivocarnos, las elecciones al Parlamento Europeo del próximo año no serán todavía verdaderamente europeas.

\section{B. Una ley provisional: la Ley Orgánica 1/1987, de 2 de abril, de regulación de las elecciones al Parlamento Europeo}

En este marco, la Ley Orgánica 1/1987, de 2 de abril, de modificación de la Ley Orgánica 5/1985, de 19 de junio, del Régimen Electoral General, para la regulación de las elecciones al Parlamento Europeo es una ley provisional que deberá ser sustituída en su momento por la regulación electoral uniforme.

Su acelerada tramitación parlamentaria ${ }^{6}$-tres meses desde la publicación del proyecto en el B.O.C.G. hasta la aprobación definitiva por el Pleno del Congreso de los Diputados- se explica por el mantenimiento de las líneas generales de la Ley Orgánica del Régimen Electoral General, con el objetivo de asegurar la mayor uniformidad posible de los distintos procesos electorales ${ }^{7}$. Dos cuestiones, sin embargo, centraron los debates: la circunscripción electoral y la prohibición del doble mandato.

En cuanto a la primera de las cuestiones, la opción por la circunscripción nacional - del mismo modo que los pequeños paises comunitarios y Francia- se impuso frente a las propuestas de circunscripción múltiple

5 Para un detenido examen de estos proyectos, véase F. SANTAOLALLa LOPEz. Elección en España del Parlamento Europeo. Civitas. Madrid, 1987. págs. 63-73; y J.L. RuIz Navarro PINAR. La Ley Orgánica de elecciones al Parlamento Europeo: sus principales aspectos y concordancia con las legislaciones electorales de los Estados miembros y los proyectos de procedimiento electoral uniforme. Boletín de Derecho de las Comunidades Europeas. Número extraordinario (1987).

"Véase «Elecciones al Parlamento Europeo». Trabajos Parlamentarios. Edición preparada por E. ARnaldo Alcubilla. Publicaciones del Congreso de los Diputados. Madrid, 1987.

Véase la intervención del Vicepresidente del Gobierno en el Pleno del Congreso de los Diputados, en la presentación del proyecto. Diario de Sesiones del Congreso de los Diputados. Núm. 33, de 26 de febrero de 1987, páginas 1.865 y siguientes. 
de los grupos nacionalistas y regionalistas, por dos razones fundamentales: el carácter de la elección a la Asamblea de una comunidad supranacional y el respeto de la proporcionalidad, que se rompería de adoptar el distrito autonómico ${ }^{8}$. La configuración autonómica del Estado español se refleja sin embargo en dos preceptos: a) el art. 221.4 que faculta a las entidades políticas para que en el momento de la presentación de candidaturas ante la Junta Electoral Central hagan constar el ámbito territorial en el que desean la difusión de sus papeletas, cuando sea inferior al estatal y siempre que coincida al menos con las secciones electorales existentes en una Comunidad Autónoma. Esta disposición tiene, a nuestro juicio, un alcance insignificante y una utilidad escasa para las entidades políticas que presenten su opción electoral al Parlamento Europeo, por cuanto su difusión limitada no tiene otra ventaja que la prevista en el art. 220.2, es decir, que la lista que se presente no sea completa; b) el confuso art. 222, que dispone que: "Los partidos, federaciones, coaliciones o agrupaciones de electores podrán hacer constar, en el momento de presentación de la candidatura ante la Junta Electoral Central, su voluntad de que en determinadas secciones electorales coincidentes con el territorio de alguna de las Comunidades Autónomas se expresen únicamente los nombres de los candidatos y suplentes miembros de partidos o de sus organizaciones territoriales, con ámbito de actuación estatutariamente delimitado a dicho territorio, así como, en su caso, su propia denominación, sigla y símbolo". Este precepto no es propiamente una concesión a los partidos nacionalistas o regionalistas por la opción por la circunscripción nacional ya que, salvo en el caso de coaliciones entre los mismos, sus candidaturas presentarán siempre los mismos nombres y la misma denominación, sigla y símbolo, sino que se justifica esencialmente desde el punto de vista de los partidos políticos federados con otros de ámbito nacional que -en el ámbito de una Comunidad Autónoma determinada - desean presentar una lista distinta de la nacional a fin de preservar formalmente su independencia relativa.

La segunda cuestión, la prohibición del doble mandato, originó un más agrio debate durante la tramitación parlamentaria de la ley. El proyecto de ley preveía la incompatibilidad entre el escaño europeo y el nacional o autonómico (art. 211.2.c y d) y asimismo la prohibición de presentación simultánea de la candidatura al Parlamento Europeo y a cualquiera de las Cámaras de las Cortes Generales o a las Asambleas Legislativas de las Comunidades Autónomas (art. 210.2), si bien esta última prohibición desaparece en el dictamen de la Comisión de Constitución del Senado; al art. 211 se añade - en el Informe de la Ponencia designada por la Comisión

a F. Santaolalla Lopez en Elección en España del Parlamento Europeo. ob. cit. pág. 97 califica el sistema instaurado de proporcional puro, al suprimirse la barrera del 3 por 100 de los votos para participar en el reparto. Del mismo autor véase también, Reflexiones sobre la normativa española para las elecciones al Parlamento Europeo. Revista de las Cortes Generales núm. 9 (1986), pág. 299 y siguientes. 
Constitucional del Congreso de los Diputados - un apartado en virtud del cual se suprime toda posibilidad de opción entre el escaño europeo y el nacional o autonómico, al disponer que la incompatibilidad habrá de resolverse en favor de la condición adquirida en último término. De hecho, la incompatibilidad entre el escaño europeo y el nacional o autonómico se transformaba en una inelegibilidad encubierta al eliminarse la facultad de opción ${ }^{9}$.

Aunque, como pone de relieve RuIz-NavarRo PINAR, la Ley Orgánica 1/1987 que regula las elecciones al Parlamento Europeo se adecúa en líneas generales con bastante rigor a los proyectos de procedimiento electoral uniforme de la Asamblea comunitaria -marco legal uniforme que resulta imprescindible para que la Asamblea de Estrasburgo se convierta en la Asamblea de los europeos más que en la Asamblea de los Estados de Europa- presenta sin embargo algunos puntos de singular relevancia en que se aparta de los mismos: por un lado, el no reconocimiento del derecho de sufragio activo y pasivo a los ciudadanos de otros Estados miembros de la Comunidad que tuvieran residencia en España; por otro, el mantenimiento del sistema de listas electorales cerradas $y$ bloqueadas ${ }^{10}$.

A los mismos añadiriamos la prima a las fuerzas políticas con representación en los órganos representativos estatales, autonómicos, provinciales o locales (art. 220.3) o el hecho de que para la distribución de espacios gratuitos de propaganda electoral en los medios de comunicación de titularidad pública se tomen en cuenta, para las primeras elecciones al Parlamento Europeo, por «últimas elecciones equivalentes», las de las elecciones municipales (disposición transitoria sexta en relación con el art. $63)^{10 b i s}$. Ambas disposiciones se inspiran en uno de los inveterados principios del derecho electoral positivo, la consolidación del mapa político existente.

9 Esta prohibición del doble mandato plantea serias dudas a la luz del art. 5 del Acta de 20 de septiembre de 1986 -a la que se remite sin embargo el art. 220.2.a) de nuestra Ley Orgánica- relativa a la elección de representantes en la Asamblea por sufragio universal directo, y que establece: «La calidad de representante en la Asamblea será compatible con la de miembro del Parlamento de un Estado miembro". No obstante, algunos países, Grecia y Bélgica además de España, han establecido la incompatibilidad.

10 J.L. Ruiz Navarro PINAR. La Ley Orgánica de elecciones al Parlamento Europeo. op. cit. pág. 33. Sobre la débil justificación del sistema de listas cerradas y bloqueadas, véase mi artículo "Profundizar en la democracia». Ya, 28 de septiembre de 1987.

10bis Ello es consecuencia de la convocatoria simultánea, como se señala más adelante, de las elecciones al Parlamento Europeo y las elecciones locales, supuesto previsto en el referido art. 63.5 . 


\section{ELECCIONES AL PARLAMENTO EUROPEO CONVOCADAS POR REAL DECRETO 504/1987, DE 13 DE ABRIL}

En cumplimiento del art. 28.1 del Acta de Adhesión de España y Portugal a las Comunidades Europeas, y diez días más tarde de la publicación en el B.O.E. de la Ley Orgánica $1 / 1987$ de regulación de las elecciones al Parlamento Europeo, se dicta el Real Decreto 504/1987, de 13 de abril, por el que se convocan elecciones de diputados al Parlamento Europeo, decreto en el que se establece la fecha de celebración (el día 10 de Junio) la misma en que se celebran las elecciones locales y a diversos Parlamentos Autonómicos, se reitera el número de eurorrepresentantes a elegir (sesenta), se determina el periodo en que tendrá lugar la campaña electoral asi como la normativa aplicable a las elecciones ${ }^{11}$.

Estas elecciones al Parlamento Europeo tienen singular importancia desde el punto de vista de la fijación de criterios interpretativos de la legislación electoral, precisamente por el hecho de ser las primeras en que

1 Conforme al art. 4 del Real Decreto 504/1987, de 13 de abril: «Las elecciones convocadas por el presente Real Decreto se regirán por la Ley Orgánica 5/1985, de 19 de junio, del Régimen Electoral General, modificada por la Ley Orgánica 1/1987, de 2 de abril, para la regulación de las elecciones al Parlamento Europeo; el Real Decreto 1.732/1985, de 24 de septiembre, por el que se regulan las condiciones de los locales y las características oficiales de los elementos materiales a utilizar en los procesos electorales, modificado por el Real Decreto 2.224/1986, de 24 de octubre, y Real Decreto 507/1987, de 13 de abril; el Real Decreto $1.733 / 1985$, de 24 de Septiembre, sobre solicitud del voto por correo en casos de enfermedad o incapacidad que impida formularlo personalmente, y por la restante normativa de desarrollom. Con posterioridad se dictan otras disposiciones por las que se rige asimismo la convocatoria electoral al Parlamento Europeo:

- Real Decreto 507/1987, de 13 de abril, por el que se modifica parcialmente el Real Decreto $1.732 / 1985$, de 24 de septiembre, por el que se regulan las condiciones de los locales y las características oficiales de los elementos materiales a utilizar en los procesos electorales.

- Real Decreto 509/1987, de 13 de abril, por el que se dictan normas complementarias para el desarrollo de las elecciones al Parlamento Europeo, elecciones locales y a los Parlamentos de las Comunidades Autónomas de Aragón, Canarias, Cantabria, Castilla y León, Castilla-La Mancha, Extremadura, Islas Baleares, La Rioja, Madrid, Murcia, Navarra, Principado de Asturias y Valencia.

- Orden de 11 de mayo de 1987, por la que se dictan normas en relación con el franqueo y depósitos en el servicio de correos de los envíos de propaganda en las elecciones a diputados al Parlamento Europeo, elecciones locales y elecciones a los Parlamentos, Asambleas o Cortes de diversas Comunidades Autónomas.

- Orden de 11 de mayo de 1987, por la que se dictan normas sobre colaboración del servicio de correos en las elecciones convocadas por Real Decreto 504/1987, de 13 de abril (Corrección de errores, B.O.E. núm. 123, de 23 de mayo siguiente).

- Orden de 15 de mayo de 1987, por la que se autoriza la gratuidad de determinados servicios telefónicos, con motivo de las elecciones de diputados al Parlamento Europeo, elecciones locales y elecciones a los Parlamentos de diversas Comunidades Autónomas.

- Real Decreto 631/1987, de 15 de mayo, por el que se concede franquicia postal y telegráfica para los radiotelegramas barco-tierra originados por los navegantes con motivo de elecciones de diputados al Parlamento Europeo, elecciones a los Parlamentos de diversas Comunidades Autónomas. 
se aplica una nueva ley electoral, con los problemas añadidos a un proceso electoral que ello comporta.

A continuación recogemos las instrucciones, resoluciones y acuerdos adoptados por la Junta Electoral Central ${ }^{12}$, órgano al que corresponde fijar los criterios esenciales para una interpretación auténtica de la legislación electoral, en relación expresa a la referida convocatoria electoral. No se incluyen por tanto otros acuerdos adoptados por la Junta Electoral Central con ocasión de los varios procesos electorales convocados, que no guardan relación directa e inmediata con las elecciones al Parlamento Europeo.

\section{A. Derecho de sufragio pasivo. Inelegibilidades e incompatibilidades}

- Consulta sobre opción por incompatibilidad entre los cargos de diputado al Parlamento Europeo y al Parlamento Autonómico (Acuerdos de 18 de mayo de 1987 y de 5 de junio de 1987).

La Junta acuerda que, de conformidad con io dispuesto en el artículo 211.3 de la Ley Orgánica del Régimen Electoral General, no hay lugar a la opción, sino que, en tal supuesto, la «incompatibilidad se resuelve a favor de la condición parlamentaria adquirida en último término».

- Consulta sobre la compatibilidad del cargo de diputado al Parlamento Europeo y concejal de Ayuntamiento (Acuerdo de 30 de junio de 1987).

La Junta acuerda que la Ley no establece tal supuesto de incompatibilidad entre el cargo de diputado al Parlamento Europeo y el de concejal de Ayuntamiento.

\section{B. Administración electoral}

- Consulta sobre validez de determinados borradores de documentos de carácter electoral (Acuerdo de 3 de abril de 1987).

12 Véanse E. ARNALdo AlcubillaA. Crónica electoral: referéndum convocado por Real Decreto 214/1986, de 6 de febrero, sobre la incorporación de España a la Alianza Atlántica. Revista de las Cortes Generales, núm. 8 (1986). Crónica electoral: elecciones generales convocadas por Real Decreto 794/1986, de 22 de abril. Revista de Derecho Político núm. 25 (1988); Crónica electoral; régimen electoral local. Revista de las Cortes Generales núm. 11 (1987); Crónica electoral: elecciones al Parlamento Europeo, locales y autonómicas celebradas el 10 de junio de 1987 (I) y (II). Revista de las Cortes Generales, núms. 12 y 13 (1987-1988); Crónica electoral: elecciones al Parlamento de Cataluña. Revista de las Cortes Generales, núm. 14 (1988). 
La Junta acuerda comunicar a la entidad política consultante que la competencia de la Junta se refiere a consultas sobre cuestiones de carácter general que supongan interpretación de la Ley, pero no debe extenderse a la calificación de documentos o borradores de los mismos.

- Consulta sobre competencia de las Juntas Electorales Provinciales y de Zona y de la Comunidad Autónoma como consecuencia de la coincidencia de varios procesos electorales (Acuerdo de 24 de abril de 1987).

La Junta acuerda que, vistos los términos del artículo 15.1 de la Ley Orgánica del Régimen Electoral General (L.O.R.E.G) y del art. 3 del Real Decreto 509/1987, de 13 de abril, las Juntas Electorales Provinciales y de Zona ejercerán en cada uno de los procesos electorales las competencias que les atribuye la L.O.R.E.G., correspondiendo por su parte a la Junta Electoral de la Comunidad Autónoma las competencias que le reconoce la ley Electoral propia de dicha Comunidad ${ }^{13}$.

- Consulta sobre la posibilidad de utilización de impresos bilingües por las Juntas y Mesas Electorales (Acuerdo de 29 de mayo de 1987).

La Junta acuerda que los citados impresos deberán ajustarse al modelo oficial aprobado por Real Decreto 507/1987, de 13 de abril ${ }^{14}$.

\section{Procedimiento electoral. Presentación y proclamación de candidaturas}

- Consulta sobre ante qué Junta Electoral es necesario constituir una coalición (Acuerdo de 30 de enero y 3 de abril de 1987).

En cuanto a la Junta Electoral competente para constituir coaliciones, esta Junta Electoral Central tiene reiteradamente acordado que si el ámbito de la coalición comprende más de una provincia, la Junta Electoral competente, para hacer constar su constitución, es la Junta Electoral Central; en caso de que la coalición se circunscriba a una sola provincia, cabe hacer

13 En la convocatoria electoral al Parlamento Europeo, la Junta Electoral Central asume, además de sus competencias propias u ordinarias en todo proceso electoral, algunas de las competencias características de las Juntas Electorales Provinciales. Así, en materia de presentación y proclamación de candidaturas, papeletas y sobres electorales y escrutinio general (arts. 220 a 224 de la Ley Electoral).

14 Conforme al Real Decreto 507/1987, de 13 de abril-que en sus arts. 3 y 4 prevé el carácter bilingüe de las papeletas y sobres electorales en las Comunidades Autónomas que tengan estatutariamente reconocida la cooficialidad de una lengua distinta del castellano y en las zonas vascoparlantes de Navarra establecidas por la Ley Foral 18/1986, de 15 de diciembre - los impresos (actas, certificaciones, listas y otros documentos) no tienen carácter bilingüe. 
constar su constitución tanto ante la Junta Electoral Central como ante la Junta Electoral Provincial ${ }^{15}$.

- Consulta sobre la posibilidad de ser candidato simultáneamente a las elecciones al Parlamento Europeo, autonómicas y locales convocadas simultáneamente (Acuerdo de 24 de abril de 1987).

La Junta acuerda que en cuanto a la presentación de candidaturas - con independencia de las inelegibilidades previstas en la Ley- la única limitación legal es la comprendida en el artículo 154.3 de la Ley Orgánica del Régimen Electoral General, en el sentido de que nadie puede presentarse simultáneamente como candidato al Congreso de los Diputados y al Senado.

- Consulta sobre posibilidad de constituir una coalición electoral con el nombre de un partido político ya existente que no concurre a la convocatoria electoral y que no formulará oposición (Acuerdo del 24 de abril de 1987).

La Junta acuerda que la denominación de una coalición, en cuanto a su posible coincidencia con el nombre de un partido político que no forma parte de la misma, es cuestión de orden público que afecta a los derechos de los electores y a la transparencia del proceso electoral, por lo que no puede admitirse -aunque no se oponga el partido político titular de la denominación- una coalición con denominación coincidente.

Igualmente, debe entenderse que una vez constituida válidamente una coalición, no cabe cambiar la denominación de la misma a lo largo del proceso electoral.

- Consulta sobre posibilidad de que una coalición electoral integrada por dos partidos políticos utilice como denominación solamente la de uno de los partidos coaligados, con independencia de que, junto con el nombre de cada candidato, se haga constar el partido a que pertenece (Acuerdo de 24 de abril de 1987).

La Junta acuerda que no cabe admitir tal posibilidad por cuanto la denominación de una coalición es cuestión de orden público que afecta a los derechos de los electores y a la transparencia del proceso electoral y no cabe inducir a confusión del electorado.

- Consulta sobre requisitos necesarios para la validez de las firmas de presentación de candidaturas al Parlamento Europeo (Acuerdo de 24 de abril de 1987).

15 La Junta Electoral competente para la constitución de coaliciones para las elecciones al Parlamento Europeo es, por tanto, la Junta Electoral Central. 
La Junta acuerda que deberán cumplimentarse a tal fin los datos y menciones, junto con la firma del elector, que constan en los impresos oficialmente aprobados al respecto como anexos al Real Decreto $507 /$ $1987^{18}$.

- Acuerdo de 24 de abril de 1987 por el que la Junta Electoral Central toma razón de la constitución de coaliciones electorales para las elecciones al Parlamento Europeo, y las elecciones municipales, y, asimismo, de dar traslado de dicha relación, con expresión de la denominación de la coalición, representantes, partidos que la integran, símbolo y siglas, ámbito territorial y proceso o procesos electorales a las Juntas Electorales correspondientes.

- Consulta sobre si una vez presentadas las candidaturas es posible solicitar se altere el orden de colocación de los candidatos, efectuando esta solicitud antes de la expresión del plazo de presentación de las candidaturas (Acuerdo de 11 de mayo de 1987).

La Junta acuerda que, conforme al artículo 48.1 de la Ley Electoral, las candidaturas no pueden ser objeto de modificación una vez que se ha efectuado su presentación, salvo en el plazo habilitado para la subsanación de irregularidades previsto en el artículo 47 y únicamente por fallecimiento, renuncia del titular o como consecuencia del propio trámite de subsanación, lo que implica que no puede efectuarse cambio alguno en el orden de colocación de los candidatos, una vez presentada la candidatura, aunque dicha solicitud de cambio se haga dentro del plazo de presentación de candidaturas, con las excepciones antes referidas.

- Consulta sobre número de suplentes integrantes de una candidatura (Acuerdo de 11 de mayo de 1987).

La Junta acuerda que, de conformidad con el artículo 46.3 de la Ley Electoral, cuando la presentación de candidaturas se realice mediante el sistema de lista, la misma debe incluir tantos candidatos como cargos a elegir y, además, tres suplentes, con expresión del orden de colocación de todos ellos, siendo en todo caso la ausencia de designación de los mismos una irregularidad subsanable en el trámite previsto por la Ley Electoral.

18 De acuerdo con el articulo 220.3 de la Ley Electoral, los partidos, coaliciones, federaciones o agrupaciones de electores que pretendan presentar candidaturas al Parlamento Europeo, y no puedan aportar la firma de cincuenta cargos electos, necesitan acreditar las firmas de 15.000 electores.

EI Real Decreto 507/1987, de 13 de abril, en el anexo EPE 5.2.a, establece los siguientes datos y menciones: nombre y apellidos del elector, número del D.N.I., firma y datos censales (número de lista, sección, distrito, municipio y provincia). Aunque la exigencia de los datos censales no parece criticable, al exigir contar con la certificación correspondiente de la Oficina del Censo Electoral, no facilita la obtención del número de firmas necesarias para la presentación ulterior de la candidatura. 
En el supuesto de que se incluyan más de tres suplentes, se comunicará al representante de la candidatura para que los reduzcan a tres, $y$, en su defecto, la Junta correspondiente entenderá que son suplentes los tres primeros.

- Escrito del representante de una entidad política en el que solicita la corrección de las listas electorales al Parlamento Europeo presentadas por la misma (Acuerdo de 11 de mayo de 1987).

La Junta acuerda que no es posible efectuar el cambio en el orden de colocación de los candidatos solicitada por el representante general de la coalición citada, ya que el artículo 48.1 de la Ley Electoral establece que las candidaturas no pueden ser objeto de modificación una vez presentadas, salvo en el plazo habilitado para la subsanación de irregularidades previsto en el artículo 47 y únicamente en los supuestos que el artículo 48 establece, en ninguno de los cuales se encuentra la posibilidad de cambio del orden de colocación de candidatos referida.

- Recurso de un partido político contra las candidaturas presentadas por otro con denominación semejante a la del recurrente (Resolución de 11 de mayo de 1987).

La Junta acuerda desestimar el recurso por cuanto inscrito el partido, cuyas candidaturas se impugnan en el Registro de Partidos Políticos, no es competencia de la Junta resolver sobre la validez de las inscripciones en el citado Registro.

- Acuerdo de 11 de mayo de 1987 de la Junta Electoral Central de proclamación de candidaturas para las elecciones al Parlamento Europeo ${ }^{17}$.

- Reclamación de una entidad política contra la inclusión de una frase en la denominación de la candidatura que pudiera inducir a confusión del electorado (Resolución de 11 de mayo de 1987).

La Junta, examinada la reclamación, así como las alegaciones formuladas por el partido político contra el que la misma se dirige, acuerda estimar la reclamación por entender que no consta la inscripción en el Registro de Partidos Políticos de la frase citada, por lo que la candidatura debe ser proclamada con la denominación que consta en el Registro de Partidos Políticos.

17 Las candidaturas presentadas a las elecciones al Parlamento Europeo convocadas por Real Decreto 504/1987, de 13 de abril fueron publicadas en el «B.O.E." de 6 de mayo de 1987.

Las candidaturas proclamadas para las elecciones al Parlamento Europeo convocadas por Real Decreto 504/1987, de 13 de abril fueron publicadas en el «B.O.E.» núm. 113 de 12 de mayo de 1987. Advertidos errores en el texto de las candidaturas proclamadas para las citadas elecciones, se publicó la corrección de errores en el «B.O.E." núm. 115 de 14 de mayo de 1987 y núm. 116 de 15 de mayo de 1987.

De las candidaturas presentadas (38) no se proclamaron tres como consecuencia de la no subsanación de las irregularidades en el plazo señalado por la J.E.C. 
- Recurso del representante de una de las candidaturas no proclamadas contra el acuerdo de la Junta Electoral Central de proclamación de candidaturas para las elecciones al Parlamento Europeo convocadas por el Real Decreto 504/1987, de 13 de abril (Resolución de 18 de mayo de 1987).

La Junta acuerda declarar inadmisible el recurso por carecer la Junta de competencia para su conocimiento, conforme a lo dispuesto en el artículo 49 de la Ley Orgánica del Régimen Electoral General.

\section{Campaña electoral. Utilización de medios de titularidad pública para la campaña electoral}

- Consulta sobre utilización de medios de titularidad pública para la campaña electoral por una entidad política que en anteriores consultas electorales concurrió en coalición (Acuerdos de 30 de enero, 3 de abril y 11 de mayo de 1987).

La Junta acuerda que, en el supuesto de que en unas elecciones, una de las entidades políticas que constituyeron coalición electoral en anteriores consultas concurra en solitario o coaligada con otros partidos políticos distintos, se procederá a dividir el total del tiempo que corresponda a la coalición electoral (conforme al artículo 64 de la Ley Orgánica del Régimen Electoral General) entre los partidos que la conformaban en función del número de representantes y votos obtenidos por cada uno de ellos en las anteriores elecciones.

- Acuerdo de 24 de abril de 1987 de la Junta Electoral Central de delegación de las Juntas Electorales Provinciales de las competencias previstas en el artículo 65.5 de la Ley Orgánica del Régimen Electoral General (B.O.E. núm. 109, de 7 de mayo de 1987): «A la vista de lo dispuesto en el artículo 65.5 de la Ley Orgánica 5/1985, de 19 de junio, del Régimen Electoral General, la Junta Electoral Central, en su reunión del dia 24 de abril de 1987, ha adoptado el siguiente acuerdo:

"Se delegan en las Juntas Electorales Provinciales, a los efectos de las elecciones locales convocadas por el Real Decreto 508/1987, y las elecciones al Parlamento Europeo convocadas por el Real Decreto 504/1987, de 13 de abril, las competencias reconocidas a la Junta Electoral Central por la Ley Orgánica 5/1985, de 19 de junio, del Régimen Electoral General, en orden a la distribución de espacios gratuitos de propaganga electoral en las programaciones regionales y locales de los medios de comunicación de titularidad estatal y de aquellos otros medios de ámbito similar, que tengan también el carácter de públicos; cuando la programación sea de ámbito superior al provincial, la delegación se entiende hecha en favor de 
la Junta Electoral Provincial en cuyo ámbito territorial radique el medio o el centro emisor».

- Acuerdo de 18 de mayo de 1987 de la Junta Electoral Central por el que se designa la Comisión de Radio y Televisión a la que se refiere el artículo 65 de la Ley Electoral (B.O.E. núm. 121 de 20 de mayo de 1987).

- Consulta sobre competencia para autorizar un acto de campaña electoral para las elecciones al Parlamento Europeo en una determinada ciudad (Acuerdo de 18 de mayo de 1987).

La Junta acuerda que, dado el ámbito del acto cuya autorización se solicita, no corresponde a la Junta Electoral Central la competencia para su autorización.

- Consulta sobre derecho a espacios gratuitos (Acuerdos de 18 y 22 de mayo de 1987).

La Junta acuerda que dada la referencia en los artículos 60 y siguientes de la Ley Orgánica del Régimen Electoral General a emisoras de televisión y radio de titularidad pública y no solamente estatal, hay que entender que, en los términos previstos en los preceptos correspondientes, las candidaturas al Parlamento Europeo que se presentan en todo el territorio estatal tendrán los derechos reconocidos en los preceptos aludidos en cualesquiera medios de titularidad pública.

- Consulta sobre el tiempo de espacios gratuitos a asignar a las candidaturas dada la coincidencia de elecciones (Acuerdo de 18 de mayo de 1987).

La Junta acuerda que hay que entender que se pone a disposición de las candidaturas un solo bloque de espacios por los tiempos previstos en el artículo 64 de la Ley Electoral. Por tanto, sólo se constituirá una Comisión.

El mismo criterio de unicidad hay que sostener en cuanto a la asignación de locales para actos públicos.

- Acuerdo de la Junta Electoral, vista la propuesta de la Comisión de Radiotelevisión, de distribución de los espacios gratuitos de propaganda electoral en los medios de comunicación de titularidad pública de ámbito nacional (Acuerdo de 22 de mayo de 1987).

- Escrito de un partído político, cuya candidatura al Parlamento Europeo fue proclamada, en el que manifiesta su protesta por las dificultades para materializar su presencia en los espacios gratuitos de propaganda electoral en los medios de comunicación de titularidad pública en los ámbitos nacional e inferiores, manifestando además la falta de medios para 
la grabación de los espacios asignados en algunos de esos medios (Acuerdos de 26 y 29 de mayo de 1987).

La Junta acuerda dirigirse a las Juntas Electorales Provinciales reiterando la circular cuyo envío fue ya acordado en pasadas reuniones de la Junta Electoral Central ${ }^{17 \mathrm{bis}}$.

- Denuncia de un partido político contra propaganda electoral de otra entidad política por utilización de la bandera española y consulta al respecto de varias Junitas Electorales Provinciales (Acuerdo de 22 de mayo de 1987).

La Junta, vista la denuncia así como el escrito de alegaciones del partido político denunciado, acuerda desestimar la reclamación, dado lo dispuesto en el artículo 8 de la Ley 39/1981, de 28 de octubre, que regula el uso de la bandera nacional y el de otras banderas y enseñas ${ }^{18}$.

- Consulta sobre elementos técnicos que deben poner a disposición los medios de comunicación de titularidad pública de los partidos y entidades políticas (Acuerdo de 22 de mayo de 1987).

Se acuerda que los medios de comunicación de titularidad pública, en sus distintos ámbitos de programación deben poner a disposición de las entidades políticas los instrumentos necesarios para la grabación en directo pero no para la grabación anticipada.

- Recurso de reposición de un partido político contra acuerdo de distribución de espacios gratuitos de propaganda electoral de diferentes Juntas Electorales Provinciales, que actuaban por delegación de la Central

176is El acuerdo se remite a los de 18 y 22 de mayo reproducidos en la página anterior y se tradujo en la siguiente circular: "Comunicole que la Junta Electoral Central tiene reiteradamente acordado que las candidaturas proclamadas en las elecciones al Parlamento Europeo y que no se acojan a lo dispuesto en el artículo 221 y de la Ley Electoral tienen el derecho reconocido en el artículo 64.1 de la citada Ley en cada uno de los medios de titularidad pública de ámbito de difusión limitado así como en cada uno de los ámbitos de programación de los medios de titularidad pública estatales; las candidaturas al Parlamento Europeo que no se acojan a lo dispuesto en el artículo 221.4 tendrán el mismo derecho en el ámbito de la Comunidad Autónoma en el que se difundan sus papeletas".

18 Este acuerdo fue recurrido en reposición ante la J.E.C. que lo desestimó en su reunión de 29 de mayo de 1987.

Varias Juntas Electorales Provinciales estimaron inicialmente la reclamación mediante acuerdos que fueron recurridos ante la J.E.C., que ratifico su criterio (resolución de 29 de mayo) de acuerdo con lo dispuesto en el artículo 8 de la Ley 39/1981 de 28 de octubre que establece la prohibición de "utilización en la bandera de España de cualesquiera símbolo y siglas de partidos políticos, sindicatos, asociaciones o entidades privadas". Así pues se prohibe no utilizar la bandera de España en los medios de propaganda electoral sino incluir en la misma símbolos partidistas o de cualesquiera otras entidades asociativas. No es, en consecuencia la aplicación el artículo 46.5 de la Ley Electoral, porque el ámbito de este precepto es distinto, la presentación de candidaturas: “No pueden presentarse candidaturas con simbolos que reproduzcan la bandera o el escudo de España, o con denominaciones o símbolos que hagan referencia a la Corona". 
conforme al artículo 65.5 de la Ley Electoral (Resolución de 29 de mayo de 1987).

La Junta se da por enterada del desistimiento del recurso en cuanto al acuerdo de una de las Juntas Electorales Provinciales y estima los demás recursos, reconociendo por tanto al partido recurrente el derecho a los tiempos de emisión conforme al artículo 64.1.2.) de la L.O.R.E.G. en cualesquiera medios de comunicación de titularidad pública de ámbito inferior al estatal y en la programación de los medios estatales del mismo ámbito inferior al estatal.

- Circular de 29 de mayo de 1987 de la Junta Electoral Central dirigida a todas las Juntas Electorales Provinciales poniendo de manifiesto la necesidad de velar por lo dispuesto en el artículo 55 de la Ley Electoral y de que, en su caso, ejerzan la potestad sancionadora que tienen atribuída legalmente.

- Recurso de una coalición electoral contra acuerdo de una Junta Electoral Provincial que niega a dicha coalición espacios gratuitos de campaña electoral (Resolución de 29 de mayo de 1987).

La Junta acuerda estimar el recurso por cuanto, presentándose la citada coalición a las elecciones al Parlamento Europeo en todo el territorio nacional tiene en cualesquiera medios de comunicación de titularidad pública el derecho reconocido en el artículo 64.1 de la Ley Electoral por lo que la Junta Electoral Provincial deberá asignar a la coalición recurrente los minutos correspondientes según la proporcionalidad acordada por dicha Junta.

- Recurso de un partido político contra acuerdo de la Dirección del Ente Público RTVE sobre criterios para el tratamiento informativo de las elecciones (Resolución de 29 de mayo de 1987).

La Junta acuerda desestimar el recurso por entender que los criterios acordados en el sentido de referirse a los grupos parlamentarios con representación en el Congreso de los Diputados y el Senado y Asambleas Autónomicas o entidades con representación en las corporaciones locales son conformes con las exigencias de respeto al pluralismo establecidas en el artículo 66 de la Ley Orgánica del Régimen Electoral General y con los criterios aludidos en el artículo 20.3 de la Constitución.

- Recurso de un partido político contra acuerdo de la Junta Electoral Central de 22 de mayo de 1987 de distribución de espacios gratuitos de propaganda electoral en los medios de difusión de titularidad pública de ámbito nacional (Resolución de 29 de mayo de 1987).

La Junta acuerda desestimar el recurso por cuanto el criterio de reparto de los espacios por sorteo rotativo es contrario a lo dispuesto en el artículo 67 de la Ley Electoral. 
- Recurso de un partido político contra acuerdo de la Junta Electoral Central de 22 de mayo de 1987 de distribución de espacios gratuitos de propaganda electoral en los medios de difusión de titularidad pública de ámbito nacional (Resolución de 29 de mayo de 1987).

La Junta acuerda desestimar el recurso por cuanto la pretensión de que por ser nuevas las elecciones al Parlamento Europeo todos los partidos han de ser iguales sin que ninguno puedan tener su espacio en la segunda cadena de TVE es contrario a lo dispuesto en el artículo 63.5 de la Ley Electoral, a cuyo tenor, en caso de coincidencia de elecciones al Parlamento Europeo y municipales, se tendrán en cuenta los resultados de las citadas elecciones municipales.

- Recurso de un partido político contra acuerdo de la Junta Electoral Central de 22 de mayo de 1987 de distribución de espacios gratuitos de propaganda electoral en los medios de difusión de titularidad pública de ámbito nacional (Resolución de 29 de mayo de 1987).

La Junta acuerda desestimar el recurso porque dado lo dispuesto en el artículo 63.5 de la Ley Electoral no es posible tener en cuenta los votos obtenidos en las elecciones generales de 1986 sino los de las elecciones municipales de 1983, en relación además con el artículo 67 de la citada Ley.

- Recurso de un partido político contra acuerdo de la Junta Electoral Central de 22 de mayo de 1987 de distribución de espacios gratuitos de propaganda electoral en los medios de difusión de titularidad pública de ámbito nacional (Resolución de 29 de mayo de 1987).

La Junta acuerda desestimar el recurso por cuanto el acuerdo adoptado por la misma se ajusta estrictamente a los criterios establecidos en los artículo 63 y 64 de la Ley Electoral y a las preferencias contempladas en el artículo 67 de la misma.

- Recurso de un partido político contra acuerdo de la Junta Electoral Central de 22 de mayo de 1987 de distribución de espacios gratuitos de propaganda electoral en los medios de difusión de titularidad pública de ámbito nacional (Resolución de 29 de mayo de 1987).

La Junta acuerda desestimar el recurso por cuanto el cómputo a favor de la coalición electoral de los votos obtenidos por uno de los partidos politicos integrantes de la misma en las elecciones municipales de 1983 es obligada consecuencia de la incorporación de dicho partido a la citada coalición y, por otra parte, por lo que se refiere a los espacios en la segunda cadena de TVE, supone la estricta aplicación de las preferencias concedidas en el artículo 67 en función de las necesidades del medio.

- Recurso de una coalición electoral contra acuerdo de la Junta Electoral Central de 22 de mayo de 1987 de distribución de espacios gra- 
tuitos de propaganda electoral en los medios de difusión de titularidad pública de ámbito nacional (Resolución de 29 de mayo de 1987).

La Junta acuerda desestimar el recurso por cuanto: 1. Dado lo dispuesto en el artículo 63.5 de la Ley Electoral han de tenerse presentes en las elecciones al Parlamento Europeo los resultados de las elecciones municipales de 1983.

2. De acuerdo con dicho criterio no cabe legalmente valorar los resultados obtenidos por dos de los partidos integrantes de la coalición electoral en las últimas elecciones autonómicas vascas y gallegas.

3. Los resultados obtenidos por otro de los partidos políticos integrantes de la coalición electoral en las últimas elecciones municipales han sido valorados en los términos previstos en el artículo 64 de la Ley Electoral.

4. Por lo que se refiere a los espacios atribuídos a un partido político por su participación en las anteriores municipales formando parte de una coalición electoral es obligado reconocerle los votos proporcionalmente correspondientes.

- Escrito de un partido politico en el que manifiesta que una Junta Electoral Provincial no ha atribuído espacios gratuitos de propaganda electoral a la citada entidad política, cuya candidatura al Parlamento Europeo ha sido proclamada por esta Junta Electoral Central (Acuerdo de 5 de junio de 1987).

La Junta acuerda dirigirse a la Provincial referida en el sentido de que el partido citado ostenta el derecho reconocido por el artículo 64.1 de la Ley Electoral, en relación con los medios de comunicación de titularidad pública no estatal y con la programación de ámbito territorial limitado de los medios de titularidad estatal.

\section{E. Papeletas y sobres electorales}

- Consulta sobre impresión de papeletas bilingües en las Comunidades Autónomas con segunda lengua oficial (Acuerdo de 24 de abril de 1987).

La Junta acuerda que, de conformidad con la nueva redacción dada al artículo 5 párrafo 2 del Real Decreto 1.732/1985, de 24 de septiembre por 
el artículo 4 del Real Decreto 507/1987 de 13 de abril, en los casos citados se imprimirá una sola papeleta bilingüe a no ser que en algún supuesto (elecciones municipales) ello pudiera resultar materialmente imposible, en cuyo caso se imprimirá en cada una de las lenguas oficiales.

- Consulta sobre interpretación del artículo 222 de la Ley Electoral en el sentido de si, manteniendo los mismos candidatos en todas las papeletas de las secciones electorales, se pueden expresar la denominación, símbolo y sigla correspondiente a la organización o ámbito territorial de un partido en su Comunidad Autónoma (Acuerdo de 24 de abril de 1987).

La Junta acuerda que la Ley Electoral no prohibe tal posibilidad, por lo que debe ser admitida la misma ${ }^{19}$.

- Solicitud de que se autorice que en la papeleta se reseñe únicamente, junto al nombre y apellidos del candidato, las siglas del partido al que pertenece el mismo y no la denominación completa de aquel (Acuerdo de 11 de mayo de 1987).

La Junta acuerda que el artículo 46.7 de la Ley Electoral establece que, junto al nombre de los candidatos puede hacerse constar su condición de independiente o, en caso de coaliciones, la denominación del partido al que cada uno pertenezca, de forma que es disponible por el partido que presente la candidatura el hacer o no constar la denominación completa o las siglas del mismo.

- Reclamación de un partido político sobre la traducción de la denominación del partido en las papeletas correspondientes de las Comunidades Autónomas con lengua oficial propia (Acuerdo de 22 de mayo de 1987).

La Junta acuerda, dado que los reclamantes aducen que tienen inscrita en el Registro de Partidos Políticos la traducción referida, delegar en su Presidente la resolución del recurso una vez que el citado Registro certifique sobre el extremo alegado ${ }^{20}$.

- Consulta sobre si son válidas cualquiera de las papeletas oficiales en cualquier lugar del territorio nacional indistintamente (Acuerdo de 29 de mayo de 1987).

19 El artículo 222 de la Ley Electoral dispone que: «Los partidos, federaciones, coaliciones o agrupaciones de electores podrán hacer constar, en el momento de presentación de la candidatura ante la Junta Electoral Central, su voluntad de que en determinadas secciones electorales coincidentes con el territorio de alguna de las Comunidades Autónomas se expresen únicamente los nombres de los candidatos y suplentes miembros de partidos o de sus organizaciones territoriales, con ámbito de actuación estatutariamente delimitado, a dicho territorio, así como, en su caso, su propia denominación, sigla y símbolo".

20 La resolución de la Presidencia fue estimatoria de la reclamación, a la vista de la certificación del Registro. 
La Junta acuerda que las papeletas de votación deberán ser en todo ajustadas al modelo oficial y que en las zonas que no tienen lengua oficial distinta del castellano se impriman solo en castellano.

\section{F. Apoderados e interventores}

- Consulta sobre la posibilidad de que una sola persona con una sola credencial actúe como interventor en cada Mesa a efectos de los varios procesos electorales que se celebran simultáneamente (Acuerdo de 24 de abril de 1987).

La Junta acuerda que debe admitirse tal posibilidad y dirigir por tanto circular a todas las Juntas Electorales Provinciales en el sentido de que con una sola credencial expedida a una persona y exhibida por ésta, podrá ejercer las funciones de interventor en una Mesa Electoral en relación con los varios procesos electorales que se celebren ${ }^{21}$.

- Consulta sobre a cuál de las actas debe unirse la credencial de los interventores en caso de haber votado en relación con los tres procesos electorales convocados (Acuerdo de 18 de mayo de 1987).

La Junta acuerda que puede incorporarse a cualquiera de las actas, si bien haciendo constar en las otras estas incorporaciones y la condición de interventor en relación con la elección de que se trate.

\section{G. Escrutinio en las Mesas Electorales y escrutinio general}

- Solicitud de una entidad política de admisión de presencia de observadores y técnicos de informática de los distintos grupos políticos en el recuento de votos realizados por el Ministerio del Interior y otras cuestiones (Acuerdo de 5 de junio de 1987).

La Junta acuerda denegar la solicitud formulada por cuanto la designación de interventores está legalmente prevista sólo en relación con las Mesas Electorales.

En cuanto a las solicitudes de que se facilite el programa de cómo se computan las actas al introducir los datos en el ordenador y a la revisión

${ }^{21}$ La J.E.C. en su reunión de 19 de mayo de 1986 acordó que bastaba una designación común de interventores o apoderados para los dos procesos electorales convocados.(Real Decreto 794/1986 de 22 de abril por el que se convocan elecciones al Congreso de los Diputados y al Senado y Decreto del Presidente de la Junta de Andalucía 73/1986, de 28 de abril por el que se convocan elecciones al Parlamento de Andalucia). 
por los partidos políticos de las actas una vez efectuado el cómputo oficial, se acuerda denegar tales solicitudes en cuanto el procedimiento de escrutinio general se efectúa conforme a lo previsto en los artículos 103 y siguientes de la Ley Electoral y concordantes.

- Circular dirigida por la Junta Electoral a las Provinciales recordando el orden de escrutinio para las próximas elecciones, dadas las dudas surgidas en las mismas, conforme al artículo 95.3 de la Ley Orgánica $1 /$ 1987, de 2 de abril: «En el supuesto de coincidencia de varias elecciones se procede de acuerdo con el siguiente orden: primero, las del Parlamento Europeo; después, las del Congreso de los Diputados; después, las del Senado; después, las de las entidades locales; después. las de las Asambleas Legislativas de la Comunidad Autónoma; después, las de los Cabildos Insulares».

- Solicitud de las Actas de escrutinio de las elecciones al Parlamento Europeo para su cotejo y comprobación (Acuerdo de 17 de junio de 1987).

La Junta acuerda denegar la solicitud expuesta, por cuanto la efectividad del derecho a obtener la certificación interesada tiene su cauce en la Ley Orgánica del Régimen Electoral General en relación con la actuación de las Mesas y de las Juntas Electorales Provinciales.

- Recurso interpuesto por el representante de una entidad política contra acuerdo de una Junta Electoral Provincial sobre validez de papeletas al Parlamento Europeo (Resolución de 17 de junio de 1987).

La Junta acuerda que no procede pronunciarse sobre el contenido del recurso, por cuanto, de conformidad con lo previsto en el artículo 106 de la Ley Electoral, durante el escrutinio general la Junta no puede anular ningún Acta ni voto, limitando sus atribuciones a verificar sin discusión alguna el recuento y la suma de votos admitidos en las correspondientes Secciones, según las Actas y certificaciones de las Mesas y con la excepción de lo previsto en el artículo 105.4 del citado texto legal.

- Consulta de varias entidades políticas sobre validez de papeletas homologadas de menor tamaño en relación con las elecciones al Parlamento Europeo (Acuerdo de 17 de junio de 1977).

La Junta acuerda que no procede pronunciarse sobre dicha validez una vez realizada la votación y de conformidad con lo dispuesto en la Ley Electoral en lo relativo al escrutinio de las Mesas electorales y al escrutinio general.

- Recurso contra acuerdo de una Junta Electoral Provincial que declara la validez de los sobres, utilizados por una entidad política en las elecciones al Parlamento Europeo, cuya solapa es más pequeña que la del modelo oficial y en el que no figura «1987» junto a «Elecciones al Parlamento Europeo» (Resolución de 17 de junio de 1987). 
La Junta acuerda que no procede pronunciarse sobre el contenido del recurso por cuanto, de conformidad con lo previsto en el artículo 106 de la Ley Electoral, durante el escrutinio general la Junta no puede anular ningún acta ni voto, limitando sus atribuciones a verificar sin discusión alguna el recuento y la suma de los votos admitidos en las correspondientes Secciones, según las actas y certificaciones de las Mesas y con la excepción de lo previsto en el artículo 105.4 del citado texto legal.

- Solicitud de un partido político de que le sean remitidos por correo los resultados de las elecciones al Parlamento Europeo y locales (Acuerdo de 30 de junio de 1987).

La Junta acuerda comunicar al Partido citado que, de conformidad con el artículo 108.4 de la Ley Electoral, la Junta Electoral Central procederá en el plazo que el referido precepto establece, a la publicación de resultados generales y por circunscripciones en el Boletín Oficial del Estado.

\section{H. Gastos y subvenciones electorales}

- Consulta sobre distribución de espacios y adelanto de subvenciones de los partidos que en anteriores elecciones formaban coalición y ahora se presentan por separado (Acuerdo de 11 de mayo de 1987).

La Junta acuerda reiterar su criterio adoptado en su reunión de 3 de abril del presente año en el sentido de que la distribución de espacios gratuitos de propaganda electoral en los medios públicos cuando se presenta independientemente a unas elecciones un partido que a las elecciones anteriores concurrió formando parte de una cóalición, los votos y escaños obtenidos en su día por la coalición se distribuyen entre los distintos partidos que integraron la misma en función del número de electos de cada partido a través del distrito, debiendo aplicarse el mismo criterio en relación con el adelanto de subvenciones.

- Acuerdo de 11 de mayo de 1987 de la Junta Electoral Central por el que se remite al Ministerio del Interior de conformidad con el art. 127 de la Ley Electoral, la relación de entidades políticas que han solicitado adelantos de subvenciones electorales ${ }^{22}$.

- Escrito del representante de una coalición electoral en el que solicita la legalización del libro de contabilidad en orden a las elecciones al Parlamento Europeo (Acuerdo de 21 de mayo de 1987).

22 No fue necesaria la actualización de las subvenciones de los gastos originados con ocasión de las elecciones al Parlamento Europeo, por cuanto el artículo 226 de la Ley Orgánica del Régimen Electoral General se aprobó por la Ley Orgánica 1/1987, de 2 de abril.

La Orden de 21 de mayo de 1987 fijó las cantidades actualizadas de las subvenciones a los gastos originados por actividades electorales para las elecciones locales de 10 de junio de 1987 (B.O.E. núm. 133, de 4 de junio de 1987). 
La Junta acuerda comunicar a la citada coalición que la Junta Electoral Central no tiene atribuida por ningún precepto la función de legalización de los citados libros.

\section{Proclamación de resultados}

- La Junta Electoral Central, en sesión celebrada el día 30 de junio de 1987, y de conformidad con lo dispuesto en el artículo 224.1 de la Ley Electoral, procede al recuento de los votos a nivel nacional de las elecciones al Parlamento Europeo celebradas el pasado 10 de junio, así como a la atribución de escaños correspondientes a cada una de las candidaturas y proclamación de electos. Asimismo y en cumplimiento de lo dispuesto en el art. 108.4 del citado texto legal, la Junta Electoral Central ha acordado proceder a la publicación en el Boletín Oficial del Estado de los resultados generales y por circunscripciones en las citadas elecciones, sin perjuicio de los recursos contencioso-electorales contra la proclamación de electos.

Se reproduce a continuación el resumen de los resultados de las elecciones al Parlamento Europeo convocadas por Real Decreto 504/1987, de 13 de abril, celebradas el 10 de junio de 1987, según los datos que figuran en las Actas de escrutinio general remitidas por cada una de las citadas Juntas Electorales Provinciales (B.O.E. núm. 164, de 10 de julio de 1987). 


\section{ELECCIONES ESPAÑOLAS AL PARLAMENTO EUROPEO}

Resumen de los resultados de las elecciones al Parlamento Europeo convocadas por Real Decreto 504/1987, de 13 de abril, celebradas el 10 de junio de 1987, según los datos que figuran en las actas de escrutinio general remitidas por cada una de las Juntas Electorales Provinciales.

\section{CUADRO I}

RESUREEN GENERAL

\begin{tabular}{|c|c|c|c|c|}
\hline $\begin{array}{l}\text { JUNTAS ELECTORALES } \\
\text { PROVINCIALES }\end{array}$ & ELECTORES & VOTOS VALIDOS & VOTOS NULOS & VOTOS EN BLANCO \\
\hline 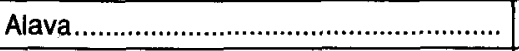 & 197.309 & 128.220 & 1.375 & 1.620 \\
\hline 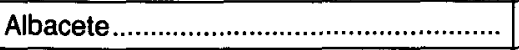 & 250.209 & 180.790 & 2.135 & 1.635 \\
\hline 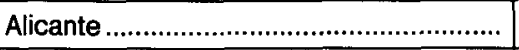 & 857.498 & 616.176 & 6.727 & 4.980 \\
\hline Almeria & 309.560 & 202.409 & 2.133 & 1.076 \\
\hline 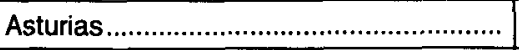 & 874.287 & 570.425 & 7.803 & 5.457 \\
\hline Avila & 143.541 & 107.285 & 1.262 & 1.014 \\
\hline Badajoz & 490.277 & 358.671 & 3.651 & 2.849 \\
\hline 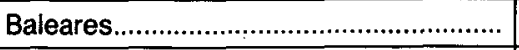 & 507.956 & 334.549 & 4.585 & 3.796 \\
\hline 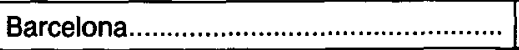 & 3.462 .191 & 2.329 .243 & 19.931 & 20.713 \\
\hline 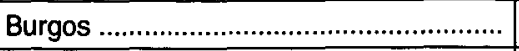 & 280.606 & 194.446 & 3.586 & 3.592 \\
\hline 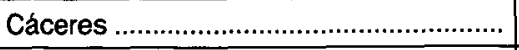 & 318.377 & 235.916 & 2.220 & 1.619 \\
\hline 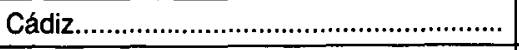 & 712.452 & 408.382 & 7.069 & 3.359 \\
\hline 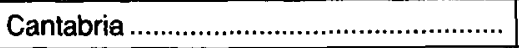 & 395.043 & 296.457 & 3.757 & 3.472 \\
\hline
\end{tabular}


CUADRO I

(continuación)

\begin{tabular}{|c|c|c|c|c|}
\hline $\begin{array}{c}\text { JUNTAS ELECTORALES } \\
\text { PROVINCIALES }\end{array}$ & ELECTORES & VOTOS VALIDOS & VOTOS NULOS & VOTOS EN BLANCO \\
\hline 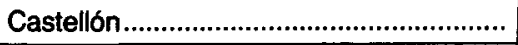 & 329.725 & 249.952 & 2.950 & 2.655 \\
\hline 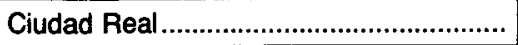 & 362.515 & 258.001 & 2.903 & 2.718 \\
\hline 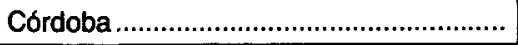 & 546.475 & 385.998 & 3.902 & 2.285 \\
\hline 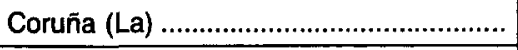 & 856.521 & 488.984 & 6.801 & 6.014 \\
\hline Cuenca & 167.803 & 125.438 & 1.483 & 1.469 \\
\hline 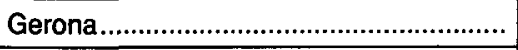 & 363.669 & 249.311 & 2.605 & 3.221 \\
\hline 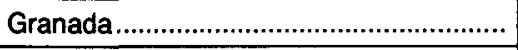 & 567.208 & 370.514 & 4.924 & 2.285 \\
\hline 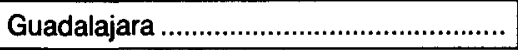 & 112.597 & 84.669 & 1.225 & 900 \\
\hline 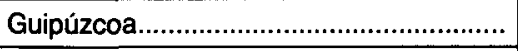 & 522.561 & 353.185 & 2.890 & 3.128 \\
\hline 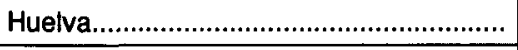 & 308.765 & 190.568 & 1.955 & 1.521 \\
\hline 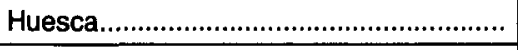 & 168.431 & 116.180 & 1.670 & 1.581 \\
\hline 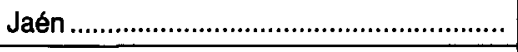 & 470.986 & 344.020 & 3.509 & 1.596 \\
\hline León ........................................................... & 411.352 & 281.352 & 3.874 & 3.948 \\
\hline 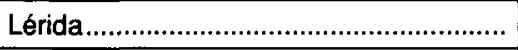 & 279.996 & 183.603 & 1.220 & 1.951 \\
\hline 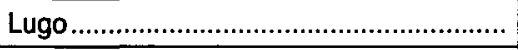 & 331.309 & 191.916 & 2.504 & 2.432 \\
\hline Madrid............................................................ & 3.515 .847 & 2.384 .028 & 33.952 & 25.960 \\
\hline Málaga & 744.076 & 439.671 & 5.941 & 3.698 \\
\hline 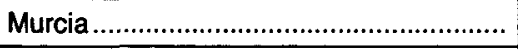 & 711.464 & 510.617 & 6.181 & 4.178 \\
\hline 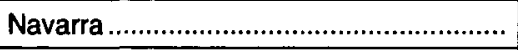 & 393.326 & 281.831 & 3.575 & 4.655 \\
\hline 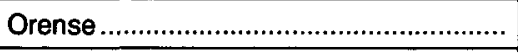 & 341.625 & 170.751 & 2.233 & 2.065 \\
\hline Palencia..... & 147.381 & 109.978 & 1.542 & 1.513 \\
\hline
\end{tabular}




\begin{tabular}{|c|c|c|c|c|}
\hline Palmas (Las) ............................................ & 515.684 & 337.176 & 5.250 & 4.824 \\
\hline 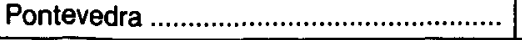 & 654.978 & 376.222 & 4.587 & 3.981 \\
\hline Rioja (La) ................................................ & 201.738 & 143.740 & 1.983 & 2.060 \\
\hline Salamanca ................................................. & 278.949 & 205.018 & 5.214 & 3.067 \\
\hline Santa Cruz de Tenerife ............................. & 488.362 & 277.974 & 2.655 & 2.016 \\
\hline Segovia ..................................................... & 117.338 & 86.622 & 1.378 & 1.810 \\
\hline 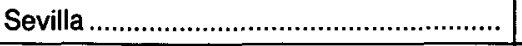 & 1.093 .270 & 724.941 & 8.045 & 4.285 \\
\hline Soria & 78.827 & 53.303 & 1.681 & 890 \\
\hline 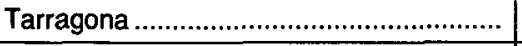 & 395.299 & 267.477 & 2.637 & 2.866 \\
\hline 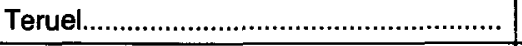 & 120.614 & 84.636 & 942 & 1.381 \\
\hline Toledo & 365.959 & 285.076 & 3.423 & 2.318 \\
\hline 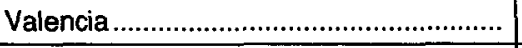 & 1.540 .621 & 1.145 .102 & 11.917 & 8.880 \\
\hline 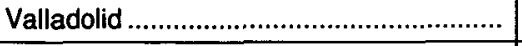 & 367.867 & 270.542 & 3.872 & 3.145 \\
\hline Vizcaya ................................................... & 891.770 & 586.723 & 6.556 & 5.484 \\
\hline Zamora & 179.155 & 129.003 & 2.341 & 1.829 \\
\hline Zaragoza......................................................... & 639.539 & 437.909 & 5.663 & 5.447 \\
\hline 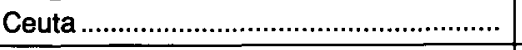 & 37.280 & 20.136 & 382 & 326 \\
\hline Melilla........................................................... & 30.303 & 18.708 & 273 & 165 \\
\hline TOTALES & 28.450 .491 & 19.193.844 & 232.872 & 189.729 \\
\hline
\end{tabular}




\section{CUADRO II}

Relación de votos correspondientes a cada uno de los partidos, federaciones, coaliciones o candidaturas que han obtenido escaños y número de éstos.

\begin{tabular}{|c|c|c|c|c|c|c|c|}
\hline $\begin{array}{c}\text { Juntas Electorales } \\
\text { Provinciales }\end{array}$ & $\begin{array}{l}\text { Partido } \\
\text { Socialista } \\
\text { Obrero } \\
\text { Español }\end{array}$ & $\begin{array}{l}\text { Alianza } \\
\text { Popular }\end{array}$ & $\begin{array}{c}\text { Centro } \\
\text { Democrático } \\
\text { y Social }\end{array}$ & $\begin{array}{l}\text { Izquierda } \\
\text { Unida }\end{array}$ & $\begin{array}{c}\text { Convergència } \\
\text { i Unió }\end{array}$ & $\begin{array}{c}\text { Herri } \\
\text { Batasuna }\end{array}$ & $\begin{array}{c}\text { Coalición } \\
\text { Europa } \\
\text { de los } \\
\text { Pueblos }\end{array}$ \\
\hline 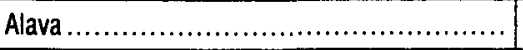 & 29.207 & 15.755 & 10.397 & 834 & 55 & 19.545 & 21.017 \\
\hline Albacete..$\ldots \ldots \ldots \ldots \ldots \ldots \ldots \ldots \ldots \ldots \ldots \ldots \ldots \ldots \ldots \ldots \ldots \ldots \ldots$ & 84.492 & 55.704 & 18.579 & 10.429 & 51 & 428 & 68 \\
\hline Alicante $\ldots \ldots \ldots \ldots \ldots \ldots \ldots \ldots \ldots \ldots \ldots \ldots \ldots \ldots \ldots \ldots \ldots \ldots \ldots \ldots$ & 267.057 & 173.769 & 79.546 & 30.596 & 693 & 2.707 & 571 \\
\hline Almería ........ & 99.052 & 48.269 & 24.276 & 13.027 & 121 & 572 & 146 \\
\hline 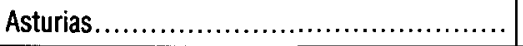 & 244.323 & 149.321 & 83.433 & 56.509 & 212 & 5.629 & 562 \\
\hline Avila $\ldots \ldots \ldots \ldots \ldots \ldots \ldots \ldots \ldots \ldots \ldots \ldots \ldots \ldots \ldots \ldots \ldots \ldots \ldots \ldots \ldots \ldots$ & 27.112 & 34.877 & 39.159 & 2.024 & 30 & 164 & 34 \\
\hline 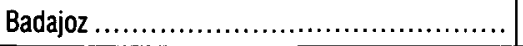 & 185.789 & 88.670 & 40.803 & 22.002 & 111 & 535 & 122 \\
\hline 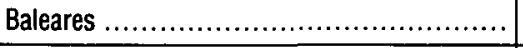 & 114.420 & 120.232 & 39.779 & 7.389 & 1.054 & 1.471 & 533 \\
\hline Barcelona.... & 904.432 & 253.713 & 135.654 & 142.022 & 588.003 & 32.262 & 80.956 \\
\hline Burgos ....... & 66.370 & 72.554 & 30.171 & 5.214 & 155 & 1.341 & 343 \\
\hline Cáceres.... & 111.125 & 66.895 & 23.759 & 5.992 & 48 & 628 & 93 \\
\hline (n) & 194.428 & 65.433 & 28.258 & 35.434 & 182 & 1.369 & 314 \\
\hline Cantabria . & 107.541 & 107.207 & 29.477 & 9.946 & 127 & 2.052 & 252 \\
\hline Castellón & 103.793 & 75.715 & 25.391 & 6.646 & 551 & 1.093 & 470 \\
\hline
\end{tabular}




\begin{tabular}{|c|c|c|c|c|c|c|c|}
\hline Ciudad Real. & 126.596 & 76.139 & 26.464 & 11.020 & 73 & 336 & 83 \\
\hline Córdoba & 168.767 & 78.474 & 35.438 & 65.166 & 129 & 796 & 177 \\
\hline 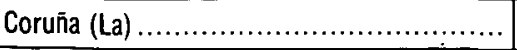 & 153.904 & 175.795 & 54.176 & 8.090 & 448 & 2.921 & 4.239 \\
\hline 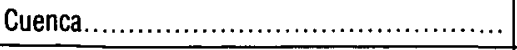 & 53.386 & 47.441 & 11.319 & 2.968 & 42 & 131 & 29 \\
\hline Gerona. & 73.342 & 21.134 & 9.496 & 6.868 & 102.351 & 2.825 & 12.341 \\
\hline Granada ........ & 170.748 & 96.375 & 29.342 & 31.701 & 102 & 1.241 & 155 \\
\hline Guadalajara & 31.501 & 35.058 & 8.729 & 3.418 & 42 & 275 & 40 \\
\hline Guipúzcoa ......................................... & 61.046 & 19.521 & 7.681 & 2.088 & 63 & 85.463 & 81.051 \\
\hline 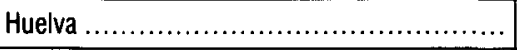 & 103.854 & 39.920 & 12.412 & 14.149 & 81 & 913 & 112 \\
\hline 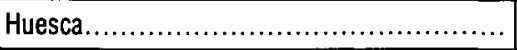 & 44.245 & 26.668 & 15.502 & 4.519 & 197 & 560 & 119 \\
\hline Jaén......... & 168.612 & 94.435 & 23.536 & 37.739 & 98 & 957 & 140 \\
\hline 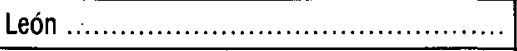 & 112.864 & 102.601 & 34.754 & 7.837 & 105 & 652 & 312 \\
\hline Lérida ................................... & 50.998 & 26.337 & 10.419 & 3.969 & 70.331 & 1.513 & 8.395 \\
\hline Lugo ..... & 41.970 & 100.800 & 17.423 & 1.462 & 128 & 683 & 1.940 \\
\hline Madrid. & 979.143 & 735.200 & 339.476 & 124.843 & 1.418 & 14.626 & 2.227 \\
\hline Málaga... & 222.721 & 92.012 & 39.392 & 48.557 & 181 & 1.446 & 254 \\
\hline Murcia ................................ & 229.984 & 163.963 & 57.106 & 28.199 & 205 & 1.309 & 265 \\
\hline Navarra. & 83.111 & 72.755 & 27.540 & 3.836 & 181 & 40.523 & 18.991 \\
\hline Orense ................... & 51.630 & 79.054 & 14.993 & 1.463 & 138 & 748 & 2.067 \\
\hline 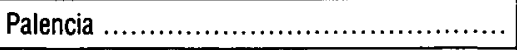 & 38.395 & 46.882 & 14.152 & 3.352 & 36 & 248 & 77 \\
\hline 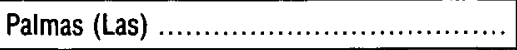 & 103.592 & 62.909 & 86.123 & 18.070 & 339 & 3.069 & 298 \\
\hline Pontevedra.. & 117.243 & 158.095 & 39.671 & 4.681 & 278 & 2.890 & 4.031 \\
\hline Rioja (La) ....................................... & 57.439 & 53.621 & 15.183 & 2.457 & 71 & 1.064 & 189 \\
\hline 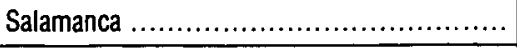 & 73.410 & 75.211 & 37.837 & 4.435 & 97 & 532 & 120 \\
\hline
\end{tabular}




\begin{tabular}{|c|c|c|c|c|c|c|c|}
\hline $\begin{array}{l}\text { Juntas Electorales } \\
\text { Provinciales }\end{array}$ & $\begin{array}{c}\text { Partido } \\
\text { Socialista } \\
\text { Obrero } \\
\text { Español }\end{array}$ & $\begin{array}{l}\text { Alianza } \\
\text { Popular }\end{array}$ & $\begin{array}{c}\text { Centro } \\
\text { Democrático } \\
\text { y social }\end{array}$ & $\begin{array}{l}\text { Izquierda } \\
\text { Unida }\end{array}$ & $\begin{array}{l}\text { Convergència } \\
\text { i Unió }\end{array}$ & $\begin{array}{c}\text { Herri } \\
\text { Batasuna }\end{array}$ & $\begin{array}{c}\text { Coalición } \\
\text { Europa } \\
\text { de los } \\
\text { Pueblos }\end{array}$ \\
\hline Santa Cruz de Tenerife. & 96.813 & 41.715 & 39.475 & 9.286 & 177 & 1.196 & 139 \\
\hline 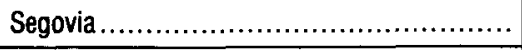 & 25.776 & 25.032 & 20.192 & 2.142 & 31 & 308 & 49 \\
\hline Sevilla.................... & 363.343 & 142.492 & 30.380 & 88.151 & 266 & 2.610 & 299 \\
\hline Soria .......... & 17.817 & 23.370 & 6.666 & 879 & 27 & 116 & 50 \\
\hline Tarragona . & 87.573 & 38.072 & 15.362 & 9.850 & 82.637 & 3.092 & 10.415 \\
\hline 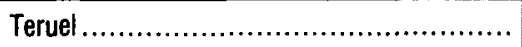 & 30.473 & 28.347 & 8.467 & 1.112 & 54 & 135 & 61 \\
\hline Toledo ...... & 122.207 & 100.675 & 30.464 & 14.973 & 82 & 361 & 84 \\
\hline Valencia .... & 474.667 & 240.950 & 105.305 & 62.192 & 1.012 & 8.447 & 1.685 \\
\hline Valladolid... & 100.287 & 86.329 & 47.517 & 8.499 & 117 & 1.173 & 132 \\
\hline 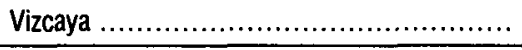 & 114.269 & 41.644 & 23.622 & 7.558 & 178 & 105.422 & 70.343 \\
\hline 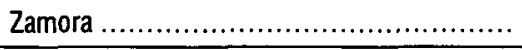 & 43.675 & 55.213 & 19.422 & 1.896 & 48 & 229 & 64 \\
\hline 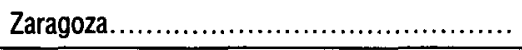 & 170.546 & 101.381 & 48.675 & 16.158 & 412 & 2.290 & 436 \\
\hline Ceuta......... & 9.034 & 6.771 & 2.191 & 180 & 24 & 30 & 17 \\
\hline Melilla.. & 8.581 & 6.778 & 1.569 & 183 & 11 & 26 & 4 \\
\hline 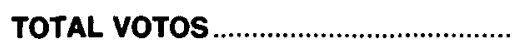 & 7.522 .706 & 4.747 .283 & 1.976 .093 & 1.011 .830 & 853.603 & 360.952 & 326.911 \\
\hline ESCAÑOS & 28 & 17 & 7 & 3 & 3 & 1 & 1 \\
\hline
\end{tabular}


CUADRO III Relación de votos correspondientes a cada uno de los partidos, federaciones, coaliciones o candidaturas que no han obtenido escaños.

\begin{tabular}{|c|c|c|c|c|c|c|c|c|c|c|c|c|}
\hline $\begin{array}{l}\text { Juntas Electorales } \\
\text { Provinciales }\end{array}$ & 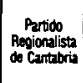 & 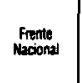 & 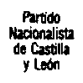 & Maling & 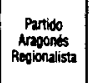 & 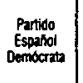 & 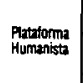 & 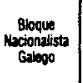 & 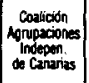 & 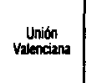 & Libercion & 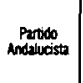 \\
\hline Alava ..... & & 256 & 141 & & 78 & 51 & 104 & 108 & 51 & 47 & 43 & 61 \\
\hline Albacefte. & & 1.682 & 50 & & 64 & 45 & 156 & 24 & 30 & 77 & 35 & 45 \\
\hline$\ldots$ & & 4.781 & 250 & & 390 & 263 & 673 & 355 & 336 & 3.260 & 251 & 391 \\
\hline Almería ,...………………………… & & 1.143 & 70 & & 90 & 105 & 92 & 90 & 131 & 87 & 213 & 4.598 \\
\hline$\ldots \ldots \ldots \ldots \ldots$ & & 2.876 & 126 & & 176 & 186 & 641 & 193 & 144 & 133 & 105 & 159 \\
\hline 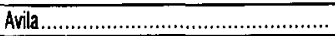 & & 538 & 144 & & 27 & 30 & 48 & 19 & 27 & 30 & 13 & 16 \\
\hline 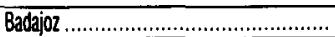 & & 1.307 & 47 & & 69 & 71 & 180 & 78 & 75 & 92 & 43 & 150 \\
\hline 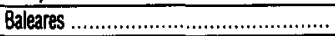 & & 781 & 142 & 19.066 & 186 & 166 & 156 & 124 & 101 & 144 & 136 & 293 \\
\hline Barcelona............................................. & & 7.674 & 2.095 & & 4.997 & 1.994 & 4.137 & 1.733 & 1.040 & 1.086 & 1.633 & 4.551 \\
\hline Burgos ................................................ & & 1.171 & 1.045 & & 179 & 174 & 253 & 118 & 112 & 90 & 95 & 94 \\
\hline 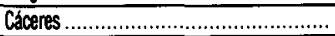 & & 792 & 66 & & 53 & 62 & 209 & 80 & 61 & 50 & 36 & 62 \\
\hline Cádiz .......................................... & & 1.470 & 145 & & 217 & 135 & 434 & 193 & 198 & 215 & 854 & 51.762 \\
\hline 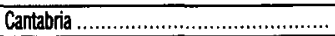 & 14.553 & 3.531 & 86 & & 121 & 105 & 415 & 84 & 92 & 78 & 40) & 94 \\
\hline Castellón............................ & & 2.611 & 67 & & 230 & 134 & 244 & 76 & 95 & 8.872 & 87 & 133 \\
\hline Ciudad Real .......................................... & & 2.866 & 84 & & 94 & 71 & 236 & 67 & 73 & 69 & 57 & 90 \\
\hline Cortoba .............................................. & & 2.602 & 88 & & 111 & 96 & 219 & 101 & 110 & 83 & 355 & 16.232 \\
\hline 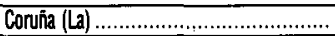 & & 1.224 & 320 & & 348 & 487 & 803 & 21.263 & 446 & 405 & 296 & 289 \\
\hline Cuenca. & & 3.173 & 48 & & 61 & 47 | & 138 & 20 & 19) & 22 & & 36 \\
\hline Gerona. & & 1.271 & 187 & & 314 & 220 & 359 & 191 & 181 & 151 & 175 & 434 \\
\hline 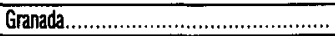 & & 3.049 & 63 & & 119 & 107 & 208 & 97 & 101 & 98 & 216 & 13.684 \\
\hline 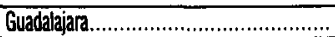 & & 825 & 37 & & 94 & 27 & 96 & 18 & 23 & 30 & 16 & 43 \\
\hline Guipuizcoa & & 439 & 183 & & 195 & 57 & 170 & 115 & 60 & 71 & 73 & 173 \\
\hline Hueva. & & 890 & 68 & & 93 & 85 & 126 & 99 & 103 & 90 & 179 & 8.980 \\
\hline Huesca. & & 371 & 28 & & 15.890 & 40 & 154 & 45 & 30 & 30 & 26 & 31 \\
\hline Jaén. & & 2.921 & 56 & & 98 & 81 & 146 & 119 & 102 & 95 & 263 & 6.123 \\
\hline Leóń............. & & 1.421 & 855 & & 112 & 133 & 224 & 141 & 86 & 97 & 74] & 91 \\
\hline Lénida.. & & 842 & 83 & & 365 & 102 & 282 & 82 & 125 & 104 & 84 & 142 \\
\hline Lugo & & 773 & 89 & & 87 & 159 & 226 & 7.522 & 200 & 80 & 87 & 93 \\
\hline Madrid . & & 29.201 & 1.185 & & 1.716 & 963 & 4.044 & 947 & 925 & 643 & 550 & 1.688 \\
\hline Málaga ................................................ & & 1.745 & 146 & & .173 & 156 & 475 & 181 & 145 & 152 & 900 & 20.602 \\
\hline Murcia ... & & 3.227 & 118 & & 184 & 196 & 532 & 119 & 170 & 368 & 150 & 151 \\
\hline Navarra. & & 1.215 & 105 & & 340 & 155 & 207 & 104 & 97 & 75 & 85 & 127 \\
\hline Orense. & & 217 & 81 & & 111 & 121 & 196 & 4.597 & 116 & $107 \mid$ & 89 & 80 \\
\hline Palenci & & 842 & 394 & & 57 & 36 & 73 & 29 & 26 & 35 & 17 & 45 \\
\hline Palmas (Las)... & & 610 & 236 & & 241 & 327 & 561 & 243 & 9.450 & 173 & 183 & 637 \\
\hline Pontevedra. & & 598 & 215 & & 238 & 268 & 613 & 12.143 & 302 & 215 & 159 & 212 \\
\hline Rioja (L & & 916 & 78 & & 146 & 64 & 87 & 40 & 60 & 46 & 24 & 42 \\
\hline Salamance & & 727 & 457 & & 104 & 71 & 320 & 69 & 71 & 59 & 54 & 59 \\
\hline Santa Crus de Tenerifle & & 784 & 113 & & 106 & 131 & 154 & 146 & 79.633 & 85 & 72 & 138 \\
\hline Segovia. & & 382 & 166 & & 43 & 50 & 73 & 26 & 40 & 34 & 34 & 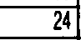 \\
\hline Sevilla. & & 2.895 & 136 & & 223 & 205 & 326 & 153 & 217 & 233 & 553 & 51.021 \\
\hline Soria. & & 129 & 223 & & 66 & 53 & 51 & 26 & 27 & 41 & 17 & 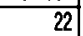 \\
\hline Tarragona & & 1.006 & 204 & & 583 & 130 & 291 & 146 & 149 & 180 & 189 & 451 \\
\hline Teruel. & & 1.007 & 39 & & 9.790 & 41 & 88 & 26 & 27 & 33 & 15 & 45 \\
\hline Toledo. & & 5.504 & 49 & & 79 & 79 & 177 & 65 & 48 & 87 & 57 & 70 \\
\hline Valencia..... & & 9.469 & 286 & & 977 & 334 & 1.073 & 302 & 821 & 143.546 & 894 & 635 \\
\hline Valladolid.. & & 3.409 & 827 & & 124 & 152 & 479 & 65 & 74 & 75 & 58 & 83 \\
\hline Vizcay & & 1.592 & 375 & & 177 & 169 & 460 & 363 & 121 & 130 & 112 & 284 \\
\hline 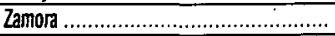 & & 926 & 346 & & 59 & 36 & 101 & 35 & 477 & 38 & 24 & 19 \\
\hline Zaragoza ............................................ & & 2.877 & 161 & & 65.431 & 154 & 787 & 119 & 130 & 119 & 100 & 163 \\
\hline Ceuta... & & 144 & 6 & & 23 & 15 & 26 & 11 & 32 & 23 & 31 & 66 \\
\hline Melilla... & & 97 & 7 & & 16 & 7 & 10 & 6 & 15 & 5 & 29 & \\
\hline TOTALES & 14.553 & 122.799 & 12.616 & 19.006 & \begin{tabular}{|l|}
105.765 \\
\end{tabular} & 9.146 & 22.333 & 53.116 & 96.895 & 162.128 & 9.891 & 185.550 \\
\hline
\end{tabular}


(continuación)

\begin{tabular}{|c|c|c|c|c|c|c|c|c|c|c|c|c|c|c|c|}
\hline 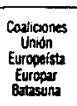 & 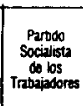 & 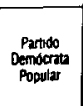 & 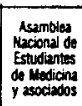 & 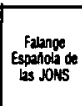 & 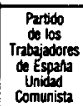 & Los Verdes & 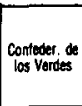 & 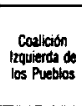 & $\begin{array}{c}\text { Extrema. } \\
\text { Unitsa }\end{array}$ & 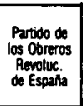 & 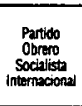 & 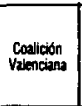 & $\begin{array}{l}\text { Paracioo } \\
\text { Action } \\
\text { Social }\end{array}$ & 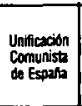 & $\begin{array}{c}\text { condidion. } \\
\text { socivivon. }\end{array}$ \\
\hline 17.982 & 454 & 683 & 286 & 80 & 707 & 571 & 336 & 11.786 & 298 & 170 & 170 & 39 & 338 & 137 & 162 \\
\hline 24 & 515 & 1.550 & 81 & 295 & 1.494 & 766 & 345 & 519 & 51 & 132 & 96 & 34 & 717 & 134 & 108 \\
\hline 344 & 2.668 & 9.480 & 796 & 1.375 & 6.042 & 7.369 & 2.643 & 4.619 & 349 & 1.321 & 715 & 1.547 & 2.744 & 807 & 689 \\
\hline 110 & 903 & 1.751 & 185 & 170 & 1.335 & 585 & 373 & 277 & 129 & 447 & 274 & 110 & 2.040 & 219 & 343 \\
\hline 333 & 2.069 & 2.931 & 2.588 & 681 & 6.467 & 2.190 & 1.210 & 1.633 & 202 & 754 & 476 & 124 & 2.475 & 680 & 884 \\
\hline 28 & 168 & 779 & 167 & 137 & 353 & 356 & 177 & 147 & 29 & 55 & 50 & 25 & 352 & 83 & 178 \\
\hline 57 & 1.142 & 2.574 & 869 & 760 & 1.632 & 1.021 & 699 & 520 & 3.709 & 876 & 236 & 99 & 955 & 255 & 274 \\
\hline 201 & 869 & 5.300 & 248 & 288 & 1.115 & 1.243 & 1.029 & 9.885 & 245 & 347 & 384 & 116 & 2.587 & 283 & 440 \\
\hline 2.634 & 14.864 & 5.549 & 3.626 & 2.136 & 21.201 & 18.374 & 17.401 & 20.282 & 4.189 & 5.869 & 5.623 & 888 & 10.430 & 3.767 & 3.712 \\
\hline 178 & 882 & 2.232 & 258 & 371 & 1.490 & 1.247 & 659 & 1.041 & 336 & 280 & 349 & 107 & 1.142 & 287 & 516 \\
\hline 72 & 682 & 1.241 & 388 & 229 & 2.042 & 703 & 356 & 306 & 16.749 & 283 & 207 & 52 & 538 & 208 & 230 \\
\hline 200 & 1.778 & 1.809 & 904 & 360 & 3.346 & 1,263 & 898 & 1.298 & 364 & 901 & 469 & 183 & 12.503 & 567 & 498 \\
\hline 284 & 1.286 & 4.720 & 445 & 733 & 3.090 & 1.008 & 501 & 1.444 & 111 & 224 & 537 & 73 & 2.080 & 290 & 358 \\
\hline 141 & 983 & 3.396 & 219 & 206 & 4.914 & 2.047 & 950 & 3.094 & 121 & 400 & 324 & 1.803 & 1.955 & 307 & 239 \\
\hline 64 & 1.179 & 4.366 & 140 & 600 & 810 & 892 & 450 & 270 & 104 & 354 & 272 & 73 & 887 & 187 & 217 \\
\hline 113 & 1.185 & 1.810 & 182 & 265 & 3.586 & 790 & 552 & 1.255 & 700 & 1.157 & 361 & 96 & 2.177 & 388 & 301 \\
\hline 2.110 & 3.596 & 13.327 & 1.568 & 648 & 6.688 & 1.723 & 1.179 & 15.792 & 376 & 821 & 1.459 & 351 & 5.349 & 1.063 & 1.466 \\
\hline 28 & 244 & 3.230 & 66 & 232 & 1.293 & 376 & 213 & 116 & 28 & 111 & 82 & 32 & 352 & 72 & 68 \\
\hline 265 & 1.791 & 791 & 342 & 250 & 999 & 1.791 & 2.693 & 1.651 & 266 & 368 & 763 & 135 & 1.323 & 303 & 519 \\
\hline 86 & 1.188 & 1.845 & 576 & 337 & 11.587 & 1.208 & 707 & 1.105 & 429 & 511 & 599 & 107 & \begin{tabular}{|c|}
3.381 \\
\end{tabular} & 275 & 346 \\
\hline 18 & 240 & 2.308 & 65 & 269 & 446 & 455 & 221 & 210 & 64 & 92 & 76 & 23 & 265 & 51 & 76 \\
\hline 44.902 & 1.053 & 389 & 378 & 122 & 2.258 & 688 & 530 & 39.799 & 368 & 225 & 252 & 34 & 191 & 233 & 286 \\
\hline 92 & 861 & 1.200 & 131 & 149 & 2.023 & 544 & 332 & 227 & 131 & 480 & 228 & 60 & 1.534 & 205 & 217 \\
\hline 62 & 442 & 1.706 & 174 & 90 & 873 & 519 & 315 & 930 & 56 & 144 & 186 & 37 & 370 & 96 & 144 \\
\hline 99 & 874 & 917 & 223 & 440 & 1.543 & 600 & 375 & 269 & 110 & 625 & 317 & 100 & 1.478 & 256 & 273 \\
\hline 1118 & 881 & 4.053 & 438 & 348 & 2.123 & 2.853 & 815 & 706 & 111 & 331 & 327 & 72 & 1.184 & 305 & 370 \\
\hline 177 & 1.013 & 582 & 275 & 141 & 691 & 1.405 & 1.677 & 1.264 & 131 & 247 & 418 & 48 & 838 & 224 & 299 \\
\hline 765 & 1.179 & 3.674 & 296 & 115 & 1.018 & 566 & 600 & 3.627 & 93 & 221 & 423 & 123 & 2.291 & 212 & 399 \\
\hline 1.913 & 6.526 & 13.222 & 4.368 & 4.034 & 53.515 & 18.551 & 9.150 & 20.558 & 3.791 & 2.847 & 1.561 & 561 & 15.296 & 1.869 & 2.264 \\
\hline 180 & 1.644 & 2.231 & 1.186 & 664 & 4.392 & 1.454 & 968 & 1.534 & 292 & 770 & 389 & 152 & 3.196 & 397 & 442 \\
\hline 148 & 1.074 & 3.232 & 264 & 566 & 1.889 & 1.882 & 939 & 1.034 & 168 & 546 & 414 & 209 & 2.633 & 501 & $5 \pi$ \\
\hline 2.574 & 1.117 & 7.906 & 330 & 218 & 1.131 & 1.364 & 860 & 9.453 & 144 & 291 & 402 & 56 & 972 & 268 & 643 \\
\hline 389 & 1.244 & 3.760 & 505 & 153 & 684 & 372 & 250 & 3.111 & 112 & 185 & 383 & 84 & 1.164 & 201 & 341 \\
\hline 46 & 241 & 536 & 119 & 174 & 913 & 397 & 225 & 226 & 61 & 123 & 111 & 22 & 388 & 95 & 134 \\
\hline 402 & 1.554 & 16.815 & 393 & 272 & 1.967 & 4.659 & 948 & 7.445 & 391 & 568 & 512 & 228 & 3.426 & 509 & 808 \\
\hline 2.058 & 2.835 & 1.905 & 622 & 536 & 4.701 & 1.180 & 883 & 13.532 & 396 & 496 & 790 & 274 & 2.859 & 579 & 724 \\
\hline 115 & 744 & 3.336 & 155 & 165 & 1.406 & 654 & 436 & 744 & 61 & 118 & 323 & 53 & 1.486 & 142 & 215 \\
\hline 85 & 528 & 1.948 & 737 & 229 & 1.362 & 1.360 & 522 & 452 & 188 & 178 & 197 & 89 & 1.048 & 230 & 297 \\
\hline 176 & 1.010 & 504 & 154 & 191 & 1.036 & 930 & 452 & 470 & 131 & 247 & 256 & 130 & 1.341 & 236 & 547 \\
\hline 38 & 291 & 7.171 & 105 & 89 & 554 & 539 & 225 & 578 & 43 & 100 & 70 & 38 & 339 & 97 & 131 \\
\hline 219 & 1.863 & 3.232 & 406 & 593 & 14.654 & 3.040 & 0.217 & 1.671 & 453 & 1.224 & 716 & 182 & 6.480 & 651 & 552 \\
\hline 25 & 176 & 1.975 & 100 & 78 & 256 & 232 & 125 & 149 & 33 & 61 & 72 & 12 & 265 & 75 & 89 \\
\hline 326 & 1.573 & 847 & 369 & 275 & 1.538 & 1.771 & 1.585 & 1.717 & 271 & 464 & 567 & 136 & 2.066 & 348 & 428 \\
\hline 27 & 399 & 781 & 54 & 85 & 766 & 325 & 163 & 254 & 23 & 87 & 103 & 19 & 219 & 88 & 102 \\
\hline 46 & 606 & 1.982 & 179 & 418 & 1.102 & 774 & 464 & 393 & 128 & 246 & 182 & 73 & 815 & 126 & 163 \\
\hline 650 & 4.135 & 5.514 & 1.221 & 1.411 & 19.763 & 10.168 & 4.809 & 17.272 & 1.409 & 2.301 & 1.019 & 5.611 & 5.408 & 1.706 & 1.230 \\
\hline 161 & 708 & 2.601 & 441 & 492 & 6.787 & 1.116 & 592 & 941 & 689 & 487 & 240 & 74 & 1.410 & 295 & 519 \\
\hline 145.251 & 1.833 & 1.101 & 1.974 & 323 & 5.456 & 1.607 & 946 & 52.730 & 480 & 464 & 571 & 87 & 714 & 431 & 472 \\
\hline 39 & 309 & 2.097 & 188 & 91 & 630 & 397 & 206 & 152 & 37 & 100 & 100 & 44 & 370 & $1+1$ & 125 \\
\hline 193 & 1.605 & 2.951 & 328 & 471 & 6.894 & 1.424 & 1.220 & 2.771 & 191 & 486 & 566 & 105 & 2.126 & 601 & 587 \\
\hline 14 & 65 & 268 & 20 & 40 & 70 & 212 & 115 & 25 & 21 & 12 & 45 & 14 & 199 & 22 & 44 \\
\hline & 63 & 758 & 11 & 12 & 48 & 64 & 38 & 44 & & 10 & & 5 & 65 & 10 & 12 \\
\hline 226.570 & $\pi .132$ & 770.8866 & 31.143 & 23.411 & 222.680 & 107.625 & 65.574 & 261.328 & 39.369 & 30.157 & 25.270 & 14.749 & 116.761 & 21.482 & 25.058 \\
\hline
\end{tabular}


Con posterioridad y como consecuencia de comunicación de la Junta Electoral Provincial de Santa Cruz de Tenerife de errores materiales en los resultados de dicha provincia en el escrutinio de las. elecciones al Parlamento Europeo, se publicó corrección de errores de los citados datos en los términos siguientes: (B.O.E. núm. 233, de 29 de septiembre de 1987):

\section{CUADRO I}

\section{RESUMEN GENERAL}

\begin{tabular}{|c|c|c|c|}
\hline Juntas Electorales Provinciales & $\begin{array}{l}\text { Votos } \\
\text { válidos }\end{array}$ & Votos nulos & $\begin{array}{l}\text { Votos en } \\
\text { blanco }\end{array}$ \\
\hline \multirow{2}{*}{ 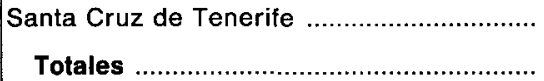 } & 320.577 & 3.311 & 2.420 \\
\hline & 19.236 .447 & 33.528 & 190.133 \\
\hline
\end{tabular}

\section{CUADRO II}

\begin{tabular}{|c|r|r|r|r|r|r|r|}
\hline $\begin{array}{c}\text { Juntas Electorales } \\
\text { Provinciales }\end{array}$ & PSOE & AP & CDS & IU & CiU & HB & $\begin{array}{r}\text { Coalición } \\
\text { Europ. P. }\end{array}$ \\
\hline $\begin{array}{l}\text { Santa Cruz } \\
\text { de Tenerife …………….... }\end{array}$ & 110.086 & 48.300 & 45.706 & 10.738 & 218 & 1.839 & 174 \\
\cline { 2 - 8 } Totales …………….... & $\mathbf{7 . 5 3 5 . 9 7 9}$ & $\mathbf{4 . 7 5 3 . 8 6 8}$ & $\mathbf{1 . 9 8 2 . 3 2 4}$ & $\mathbf{1 . 0 1 3 . 2 8 2}$ & $\mathbf{8 5 3 . 6} \mathbf{4 4}$ & $\mathbf{3 6 1 . 5 9 5}$ & $\mathbf{3 2 6 . 9 4 6}$ \\
\hline
\end{tabular}

\section{CUADRO III}

\begin{tabular}{|c|c|c|c|c|c|c|c|}
\hline $\begin{array}{l}\text { Juntas Electorales } \\
\text { Provinciales }\end{array}$ & $\begin{array}{c}\text { Partido } \\
\text { Regionalista } \\
\text { de Cantabria }\end{array}$ & $\begin{array}{c}\text { Frente } \\
\text { Nacional }\end{array}$ & $\begin{array}{c}\text { Partido } \\
\text { Nacionalista } \\
\text { de Castilla } \\
\text { y León }\end{array}$ & $\begin{array}{c}\text { Unió } \\
\text { Mallorquina }\end{array}$ & $\begin{array}{c}\text { Partido } \\
\text { Aragonés } \\
\text { Regionalista }\end{array}$ & $\begin{array}{c}\text { Partido } \\
\text { Español } \\
\text { Demócrata }\end{array}$ & $\begin{array}{l}\text { Plataforma } \\
\text { Humanista }\end{array}$ \\
\hline $\begin{array}{l}\text { Santa Cruz } \\
\text { de Tenerife }\end{array}$ & - & 912 & 141 & \multirow{2}{*}{$\begin{array}{c}- \\
(19.066)\end{array}$} & 160 & 189 & 189 \\
\hline Totales & $(14.553)$ & 122.927 & 12.644 & & 105.819 & 9. 204 & 22.368 \\
\hline
\end{tabular}

\section{CUADRO III (Continuación)}

\begin{tabular}{|c|c|c|c|c|c|c|c|}
\hline $\begin{array}{c}\text { Juntas } \\
\text { Electorales } \\
\text { Provinciales }\end{array}$ & $\begin{array}{c}\text { Bloque } \\
\text { Nacionalista } \\
\text { Galego }\end{array}$ & $\begin{array}{c}\text { Coalición } \\
\text { Agrupaciones } \\
\text { Independientes } \\
\text { de Canarias }\end{array}$ & $\begin{array}{l}\text { Unión } \\
\text { Valenciana }\end{array}$ & $\begin{array}{l}\text { Liberación } \\
\text { Andaluza }\end{array}$ & $\begin{array}{c}\text { Partido } \\
\text { Andalucista }\end{array}$ & $\begin{array}{l}\text { Coaliciones } \\
\text { Unión } \\
\text { Europeista- } \\
\text { Europar } \\
\text { Bata suna }\end{array}$ & $\begin{array}{l}\text { Partido } \\
\text { Socialista } \\
\text { de los } \\
\text { Trabajad. }\end{array}$ \\
\hline $\begin{array}{l}\text { Santa Cruz } \\
\text { de Tenerife }\end{array}$ & 183 & 91.205 & 147 & 94 & 164 & 222 & 1.365 \\
\hline Totales ............. & 53.153 & 108.467 & 162.190 & 9.903 & 185.576 & 226.616 & 77.487 \\
\hline
\end{tabular}




\section{CUADRO III (Continuación)}

\begin{tabular}{|c|c|c|c|c|c|c|c|}
\hline $\begin{array}{l}\text { Juntas Electorales } \\
\text { Provinciales }\end{array}$ & $\begin{array}{c}\text { Partido } \\
\text { Demócrata } \\
\text { Popular }\end{array}$ & $\begin{array}{c}\text { Asamblea } \\
\text { Nacional } \\
\text { de estudiantes } \\
\text { de Medicina } \\
\text { y asociados }\end{array}$ & $\begin{array}{c}\text { Falange } \\
\text { Española } \\
\text { de las } \\
\text { JONS }\end{array}$ & $\begin{array}{c}\text { Partido } \\
\text { de los } \\
\text { trabajadores } \\
\text { de España } \\
\text { Unidad } \\
\text { Comunista }\end{array}$ & Los Verdes & $\begin{array}{l}\text { Confederación } \\
\text { de los } \\
\text { Verdes }\end{array}$ & $\begin{array}{c}\text { Coalición } \\
\text { Izquierda } \\
\text { de los } \\
\text { Pueblos }\end{array}$ \\
\hline $\begin{array}{l}\text { Santa Cruz } \\
\text { de Tenerife }\end{array}$ & 621 & 193 & 240 & 1.382 & 1.204 & 605 & 672 \\
\hline Totales & 170.983 & 30.182 & 23.460 & 223.026 & 107.899 & 65.727 & 261.530 \\
\hline
\end{tabular}

\section{CUADRO III (Continuación)}

\begin{tabular}{|c|c|c|c|c|c|c|c|}
\hline $\begin{array}{c}\text { Juntas } \\
\text { Electorales } \\
\text { Provinciales }\end{array}$ & $\begin{array}{c}\text { Extremadura } \\
\text { unida }\end{array}$ & $\begin{array}{c}\text { Partido } \\
\text { de los Obreros } \\
\text { Revolucionario } \\
\text { de España }\end{array}$ & $\begin{array}{c}\text { Partido } \\
\text { Obrero } \\
\text { Socialista } \\
\text { Internacional }\end{array}$ & $\begin{array}{c}\text { Coalición } \\
\text { Valenciana }\end{array}$ & $\begin{array}{c}\text { Partido } \\
\text { Acción } \\
\text { Social }\end{array}$ & $\begin{array}{c}\text { Unificación } \\
\text { Comunista } \\
\text { de España }\end{array}$ & $\begin{array}{c}\text { Coalición } \\
\text { Socialdem. }\end{array}$ \\
\hline $\begin{array}{c}\text { Santa Cruz } \\
\text { de Tenerife ....... }\end{array}$ & 154 & 303 & 326 & 162 & 1.639 & 300 & 744 \\
\cline { 2 - 8 } Totales ........ & $\mathbf{3 9 . 3 9 2}$ & $\mathbf{3 0 . 2 1 3}$ & $\mathbf{2 5 . 3 4 0}$ & $\mathbf{1 4 . 7 8 1}$ & $\mathbf{1 1 7 . 0 5 9}$ & $\mathbf{2 1 . 5 4 6}$ & $\mathbf{2 5 . 2 5 5}$ \\
\hline
\end{tabular}

-Acuerdo de la Junta Electoral Central de 30 de junio de 1987 por el que de conformidad con lo dispuesto en el artículo 224.1 de la Ley Orgánica del Régimen Electoral General, se ha procedido al recuento de los votos a nivel nacional de las elecciones al Parlamento Europeo celebradas el 10 de junio, a la atribución de escaños correspondientes a cada una de las candidaturas y a la proclamación de electos de los siguientes señores:

1. Don Fernando Morán López (PSOE).

2. Don Manuel Fraga Iribarne (AP).

3. Don Enrique Barón Crespo (PSOE).

4. Don Manuel Medina Ortega (PSOE).

5. Don Fernando Suárez González (AP).

6. Don Eduardo Punset i Casals (CDS).

7. Don Josep Verde i Aldea (PSOE).

8. Don Luis Guillermo Perinat Elio (AP).

9. Don Luis Planas Puchades (PSOE).

10. Don Juan Colino Salamanca (PSOE).

11. Don Miguel Arias Cañete (AP).

12. Doña Ana Miranda de Lage (PSOE).

13. Don Fernando Pérez Royo (lzq. Unida).

14. Don Raul Morodo Leoncio (CDS).

15. Don Pío Cabanillas Gallas (AP).

16. Don Josep Pons Grau (PSOE).

17. Don Carles Alfred Gasoliba y Bohm (Conv. i Unió). 
18. Don Francisco Oliva Garcia (PSOE).

19. Don Antonio Navarro Velasco (AP).

20. Don Joan Colom i Naval (PSOE).

21. Doña Ludivina García Arias (PSOE).

22. Don José María Alvarez de Eulate Peñaranda (AP).

-23. Don Rafael Calvo Ortega (CDS).

24. Don José Luis García Raya (PSOE).

25. Don Domenec Romera Alcázar (AP).

26. Don José Alvarez de Paz (PSOE).

27. Don José Vázquez Fouz (PSOE).

28. Don José María Lafuente López (AP).

29. Don Antoni Gutiérrez Díaz (Izq. Unida).

30. Don Julián Grimaldos Grimaldos (PSOE).

31. Don Federico Mayor Zaragoza (CDS).

32. Don Carlos Robles Piquer (AP).

33. Doña Bárbara Duhrkop Duhrkop (PSOE).

34. Don Enrique Sapena Granell (PSOE).

35. Don Arturo Juan Escuder Croft (AP).

36. Doña Concepción Ferrer Casals (Conv. i Unió).

37. Don Mateo Sierra Bardaji (PSOE).

38. Don Xavier Rubert de Ventos (PSOE).

39. Don Pedro Argüellas Salaverría (AP).

40. Doña Carmen Díez de Rivera Icaza (CDS).

41. Don Esteban Caamaño Bernal (PSOE).

42. Don José Luis Valverde López (AP).

43. Don José María Montero Zabala (Herri Batasuna).

44. Don Carlos Bru Purón (PSOE).

45. Don Jesús Cabezón Alonso (PSOE).

46. Don Ramón Diez del Río Jaudenes (AP).

47. Don Alonso Puerta Gutiérrez (Izq. Unida).

48. Don José Emilio Cervera Cardona (CDS).

49. Don Eusebio Cano Pini (PSOE).

50. Don Juan Carlos Garaikoetxea Urriza (Coalición por la Europa de los Pueblos).

51. Don Salvador Garriga Pollero (AP).

52. Don Juan de Dios Ramirez Heredia (PSOE).

53. Don Víctor Manuel Arbeloa Muru (PSOE).

54. Doña Carmen Llorca Villaplana (AP).

55. Don Javier Sanz Fernández (PSOE).

56. Don Joaquim Muns Albuixech (Conv. i Unió).

57. Don José Coderch Planas (CDS).

58. Don Manuel Garcia Amigo (AP).

59. Don José Miguel Bueno Vicente (PSOE).

60. Don José Cabrera Bazán (PSOE).

Finalmente, la Junta ha acordado que la sesión en la que los candidatos electos presten juramento o promesa de acatamiento a la Consti- 
tución ante la misma tenga lugar el próximo día 3 de julio, a las doce treinta horas, de conformidad con lo establecido en el artículo 224.2 de la Ley Orgánica del Régimen Electoral General. 